\title{
IMPACTOS DO SISTEMA DE PAGAMENTO POR QUALIDADE DO LEITE EM UMA COOPERATIVA DA AGRICULTURA FAMILIAR
}

\author{
IMPACTS OF THE MILK QUALITY PAYMENT SYSTEM IN A FAMILY \\ AGRICULTURE COOPERATIVE
}

\section{IMPACTOS DEL SISTEMA DE PAGO POR EL CALIDAD DE LA LECHE EN UNA COOPERATIVA DE LA AGRICULTURA FAMILIAR}

\author{
Marcelo Roger Meneghatti ${ }^{1}$ \\ Aline Griebeler ${ }^{2}$ \\ Luciana Oliveira de Fariña ${ }^{3}$ \\ Geysler Rogis Flor Bertolini ${ }^{4}$
}

\begin{abstract}
RESUMO
Este estudo teve como objetivo analisar os impactos gerados pela implantação de um sistema de pagamento baseado por indicadores de qualidade implantados em uma Cooperativa da Agricultura Familiar. Trata-se de uma pesquisa qualitativa, documental e de campo, com entrevistas semiestruturadas com os três representantes da Cooperativa estudada e todos os produtores que confiam a ela seu produto. As análises das entrevistas foram realizadas por intermédio do software Iramuteq, sendo elas a Classificação Hierárquica Descente e a de Similitude de palavras. Os resultados demonstraram a importância do Sistema de Pagamento por Qualidade, principalmente por apresentar impactos socioeconômicos e técnicos, pois a qualidade do leite entregue melhorou, e os produtores trabalharam motivados pela implantação do Sistema de Pagamento por Qualidade. Como contribuição esta pesquisa aponta os impactos positivos e negativos causados pela implantação deste sistema, permitindo um novo olhar de aprimoramento e novas maneiras de uso desta forma de gestão.
\end{abstract}

Palavras-chave: Desenvolvimento Rural. Cooperativismo Sustentável. Produção de Leite.

\footnotetext{
${ }^{1}$ Doutor em Administração. Docente do Colegiado de Administração da Universidade Estadual do Oeste do Paraná (Unioeste) - Campus de Cascavel. Cascavel. Paraná. Brasil. E-mail: frmeneghatti@hotmail.com. ORCID: https://orcid.org/0000-0002-5736-4230

${ }^{2}$ Bacharel em Administração. Unioeste. Cascavel. Paraná. Brasil. E-mail: aly.griebeler@gmail.com. ORCID: https://orcid.org/0000-0002-6850-9992.

${ }^{3}$ Doutora em Ciência e Tecnologia de Alimentos. Docente do Doutorado em Desenvolvimento Rural Sustentável, do Mestrado em Ciências Farmacêuticas e do colegiado de Farmácia da Unioeste. Campus de Cascavel. Cascavel. Paraná. Brasil. E-mail: luciana.farina@unioeste.br. ORCID: https://orcid.org/0000-00025466-4887.

${ }^{4}$ Doutor em Engenharia de Produção. Docente do Doutorado em Desenvolvimento Rural Sustentável, do Mestrado Profissional em Administração, do Mestrado em Contabilidade e do colegiado de Administração da Unioeste. Cascavel. Paraná. Brasil. E-mail: geysler.bertolini@unioeste.br. ORCID: http://orcid.org/0000-00019424-4089.
}

DRd - Desenvolvimento Regional em debate (ISSNe 2237-9029) 


\begin{abstract}
This study aimed to analyze the impacts generated by the implementation of a payment system based on quality indicators implemented in a Family Agriculture Cooperative. It is a qualitative, documentary and field research, with semi-structured interviews with the three representatives of the studied Cooperative and all the producers who entrust their product to it. The analyzes of the interviews were carried out using the Iramuteq software, being the Descending Hierarchical Classification and the Similitude of words. The results demonstrated the importance of the Quality Payment System, mainly because it has socioeconomic and technical impacts, as the quality of the milk delivered has improved, and the producers worked motivated by the implementation of the Quality Payment System. As a contribution this research points out the positive and negative impacts caused by the implementation of this system, allowing a new look for improvement and new ways of using this form of management.
\end{abstract}

Keywords: Rural Development. Sustainable cooperativism. Milk production.

\title{
RESUMEN
}

Este estudio tuvo como objetivo analizar los impactos generados por la implementación de un sistema de pago basado en indicadores de calidad implementados en una Cooperativa de Agricultura Familiar. Se trata de una investigación cualitativa, documental y de campo, con entrevistas semiestructuradas a los tres representantes de la Cooperativa estudiada y a todos los productores que le confían su producto. Los análisis de las entrevistas se realizaron utilizando el software Iramuteq, siendo la Clasificación Jerárquica Descendente y la Similitud de palabras. Los resultados demostraron la importancia del Sistema de Pago de Calidad, principalmente porque tiene impactos socioeconómicos y técnicos, ya que la calidad de la leche entregada ha mejorado y los productores trabajaron motivados por la implementación del Sistema de Pago de Calidad. Como aporte esta investigación señala los impactos positivos y negativos provocados por la implementación de este sistema, permitiendo una nueva mirada de mejora y nuevas formas de utilizar esta forma de gestión.

Palavras clave: Desarrollo Rural. Cooperativismo Sostenible. Producción de Leche.

Como citar este artigo: MENEGHATTI, Marcelo Roger et al. Impactos do sistema de pagamento por qualidade do leite em uma cooperativa da agricultura familiar. DRd Desenvolvimento Regional em debate, v. 10, p. 1203-1234, 29 out. 2020. DOI: https://doi.org/10.24302/drd.v10i0.2963

Artigo recebido em: 30/06/2020

Artigo aprovado em: 07/10/2020

Artigo publicado em: 29/10/2020

DRd - Desenvolvimento Regional em debate (ISSNe 2237-9029) 


\section{INTRODUÇÃO}

O setor lácteo brasileiro passou por grandes transformações na sua cadeia produtiva ao longo dos anos. Exigências sanitárias, assim como, a ampliação da produtividade e competitividade, após a abertura comercial externa com a formação do MERCOSUL foram o princípio das grandes mudanças no setor (GIGANTE, 2004; CLEMENTE; HESPANHOL, 2008, MU et al., 2016). Consequentemente, a inserção de novas tecnologias foi essencial para atender as novas exigências e demandas do mercado.

Observando o mercado de leite e sua importância como alimento, o Ministério da Agricultura, Pecuária e Abastecimento - MAPA, com intuito de adequar às exigências mínimas de qualidade, publicou a Instrução Normativa $N^{o} 51$ - IN 51 que passou por uma recente substituição. Publicadas em 26 de novembro de 2018, as novas normativas, Instrução Normativa N 76 - IN 76 e a Instrução Normativa No 77 - IN 77, seguem tendências mundiais, regulamentando os aspectos a serem cumpridos em toda cadeia de produção leiteira (BRASIL, 2018a,b).

Esse esforço das normativas demonstra a prioridade de obter um leite que possui melhor qualidade higiênica e que apresente maior quantidade de sólidos totais, zelando por um baixo custo. A qualidade representa também menores perdas e maior valor agregado, obtendo maior vantagem competitiva (MORAES; BENDER FILHO, 2017; POPESCU; ANGEL, 2019).

A implantação de um Sistema de Pagamento por Indicadores de Qualidade do leite é uma ferramenta estratégica para as indústrias que buscam melhorar a qualidade da sua matériaprima e aprimoram o relacionamento entre indústria e produtor (FONSECA, 2001; DÜRR, 2004). Porém, quando existem falhas na estratégia de implantação deste sistema, os impactos são os prejuízos para a indústria ou para as famílias produtoras, que em grande maioria são famílias da agricultura familiar, quem veem nesta atividade uma possibilidade de diversificação de sistemas produtivos (CARBONERA et al., 2020). Portanto esta relação indústria e produtor tem um fator social importante, principalmente no sustento das famílias produtoras.

O Sistema de Pagamento por Qualidade, quando bem implantado pode solucionar problemas renda e de relacionamento entre os envolvidos, e ainda colaborar para que o processo produtivo seja eficiente (FONSECA, 2001). Além de garantir a qualidade e rendimento do seu produto final, possibilitando a diminuição de perdas da produção, para assim, se tornar competitiva ao atual mercado (ÁLVARES, 2005; WINCK, 2012).

O sistema de cooperativo tem papel importante no processamento do leite com origem na agricultura familiar, assim como na humanização da gestão para algumas cadeias produtivas (SAUSEN et al., 2019; MU; DAWANDE; MOOKERJEE, 2020). Na maioria das comunidades rurais, principalmente as marcadas pela agricultura familiar, o cooperativismo é uma alternativa de organização, comércio e agregação de valor, servindo como ferramenta para enfrentar a concorrência empresarial (COSTA; AMORIM JUNIOR; SILVA, 2015; OJIAGU; UCHENNA, 2015). Esses são os motivos para esta pesquisa investigar o pagamento pela qualidade do leite em uma cooperativa, voltada para a agricultura familiar.

No sistema cooperativo da agricultura familiar a adoção de um sistema de pagamento por qualidade pode gerar benefícios ou malefícios para cooperativa ou cooperado. Por isso, esta

DRd - Desenvolvimento Regional em debate (ISSNe 2237-9029) 
pesquisa busca compreender a seguinte questão: Quais são os impactos gerados pela implantação de um Sistema de Pagamento por Qualidade do Leite em uma Cooperativa da agricultura familiar? Para responder a esta questão o objetivo da pesquisa consiste em analisar os impactos gerados pela implantação de um Sistema de Pagamento por Qualidade do leite em uma cooperativa da agricultura familiar.

Justifica-se este estudo, pois, as pesquisas já existentes sobre o pagamento por qualidade geralmente são voltadas a eficiência do modelo e sua utilização por cooperativas e indústrias de médio e grande porte, que não trabalham o cunho social. Espera-se que os resultados da pesquisa contribuam para evidenciar a importância do Sistema de Pagamento por Qualidade e seus impactos socioeconômicos e técnicos.

Além desta introdução, o artigo está estruturado com uma revisão teórica sobre o sistema de pagamento por qualidade. A metodologia contendo as diretrizes das análises de Classificação Hierárquica Descente e a de Similitude de palavras. Por fim, a análise e discussão dos dados e as considerações finais.

\section{REVISÃO DE LITERATURA}

A Instrução Normativa n ${ }^{\circ} 51$ de 18 de setembro de 2002 teve como objetivo estabelecer os pontos peculiares a nutrição e sanidade animal, a refrigeração adequada e a higiene sanitária. Ou seja, assegurando a indústria do setor à qualidade do leite cru e a confiabilidade que os procedimentos realizados anteriormente estão em conformidade com as normativas, desde a, ordenha higiênica de vacas sadias, seguida de refrigeração adequada do leite na propriedade rural e do transporte realizado por granel em tanques isotérmicos até a indústria (DÜRR, 2004)

Desde 2009, um estudo realizado pela RBQL mostrou que, em torno de 1,7 milhões de amostras analisadas, $21 \%$ as quais não atendem as especificações do limite de 750.000 de CCS, assim como, $42 \%$ não atenderam o limite de 750.000 para o CBT. Com estes resultados demonstram que a qualidade higiênica sanitária do leite não foi encarada como uma questão estratégica para uma significativa parcela da cadeia produtiva (SANTOS, 2011a).

Ao analisar os percentuais é constatado um valor significativo dos produtores que não atenderam as especificações de redução de CCS e CBT proposta pela IN 51 (BRASIL, 2002b). Por motivo destes foi estabelecida a Instrução Normativa $n^{0} 62$ - IN 62 (BRASIL, 2011), tencionando a busca de níveis de redução para CCS e CBT, dessa maneira gradativa em termos de limites e com período de mais quatro anos para cumprimento do menor limite definido para cada região produtora do País.

Esta norma pretendia a substituição dos Regulamentos Técnicos de Identidade e Qualidade dos leites classificados como tipo B e C para o cru e refrigerado. A IN 62 passou a exigir a obrigatoriedade da realização de análises de resíduos e indicadores de antibióticos no leite em uma unidade do RBQL operacional (BRASIL, 2011). Portanto, melhorar o preço pago aos produtores de leite por meio de benefícios ou remuneração por indicadores de qualidade, tornou-se fundamental para incentivar a melhoria da qualidade do leite, atitudes que, já estão sendo adotadas em diversos países (SILVA; LISERRE, 2009). 
As alterações propostas nas Instruções Normativas $\mathrm{N}^{\mathrm{o}} 76$ e 77 trazem algumas modificações para todas as etapas da cadeia produtiva, desde a produção realizada na propriedade, até a qualidade dos leites pasteurizados (FAGNANI, 2019). Publicadas no dia 30 de novembro de 2018, as instruções normativas seguem tendências mundiais, pertinentes à produção e comercialização, vigentes desde o mês de junho de 2019 (ZÜGE, 2019).

Paranhos (2019) destacou que um dos principais impactos para o produtor é a necessidade da adequação do limite de Contagem Padrão em Placa (CPP), a já conhecida CBT (contagem bacteriana total) relacionada ao número de bactérias presentes no leite. Outro ponto importante é o CCS que passa a ter como limite máximo 500.000 cél $/ \mathrm{ml}$, também como padrão de média geométrica trimestral. No entanto, caso o CCS não esteja dentro dos parâmetros estabelecidos, não gerará a interrupção na coleta de leite. Isso porque, o CCS é um critério de qualidade sensível ao produtor, pois seu controle é mais complexo e demanda estratégias a médio e longo prazo (PARANHOS, 2019).Os preços que os lacticínios repassam aos produtores de leite são considerados base, estes são principalmente determinados pela ação do mercado (POPESCU; ANGEL, 2019). No preço base não estão contidas nenhuma bonificação. Durante mais ou menos 40 anos, o Brasil instituiu preços que garantissem o abastecimento da demanda (SILVA; LISERRE, 2009). Para empregar um Sistema de Pagamento por Qualidade é necessário estipular quais parâmetros influenciam na composição do produto, ou nos aspectos produtivos. A partir de então, estabelecer os indicadores de qualidade que beneficiará ou penalizará os produtores.

A forma de bonificação mais utilizada no Brasil é por volume de leite produzido, o que favorece, logo assim, aos maiores produtores de leite (SANTOS, 2011b). Porém, o setor observou que o produtor, respondia a estímulos como o preço do leite, principalmente, aumentando sua produção. O estímulo não correspondia a expectativa da indústria no quesito, qualidade do leite. Para isso, seriam necessárias modificações nas práticas de ordenha realizadas nas propriedades, definindo novas políticas e esclarecendo aos produtores (MARTINS, 2003).

Os parâmetros mais utilizados pelas indústrias que realizam o pagamento por qualidade são: a qualidade higiênica, a composição do leite, resíduos de antibióticos e inibidores, volume/sazonalidade e condições zootécnicas. É importante destacar que a relevância que cada parâmetro exercerá em um sistema de pagamento por qualidade, é de total responsabilidade da empresa (SANTOS; FONSECA, 2001).

No sentido composição, é necessário levar em consideração alguns procedimentos, tais como: as análises devem ser realizadas em laboratórios credenciados na Rede Brasileira de Qualidade do Leite - RBQL; a coleta de amostras deve ser realizada por profissionais qualificados, no intuito de prevenir a contaminação no processo; os resultados devem ser repassados aos produtores rurais, assegurando a transparência; e as indústrias devem disponibilizar um serviço de assistência aos produtores rurais auxiliando no âmbito técnico, para auxiliar nas boas práticas no manejo e ordenha do rebanho (SANTOS; FONSECA, 2001; BOTARO; GAMEIRO; SANTOS, 2013).

O importante a ser estudado pela indústria na elaboração de um Sistema de Pagamento por Qualidade, além de definir os parâmetros que serão indicadores de bonificar por qualidade, a indústria deverá analisar se optará por penalizar o produtor sobre o preço base, pelo leite entregue que não atingirem indicadores de qualidade necessários para a produção. O ideal é que o Sistema de Pagamento por Qualidade não contenha parâmetros diferentes dos pré- 
estabelecidos, e que a indústria não penalize o produtor que entregar sua produção fora do padrão, caso não esteja previamente acordado no Sistema de Pagamento por Qualidade (EKMAN, 2002; MU et al., 2016).

É necessário destacar, que algumas indústrias não utilizam um Sistema de Pagamento por Qualidade, e optam pela utilização de penalização, considerado inviável para algumas indústrias, tendo em vista, que os produtores podem procurar indústrias concorrentes que não utilizem um sistema de punições por indicadores de qualidade. Assim, a elaboração de um Sistema de Pagamento por Qualidade deve levar em consideração, os parâmetros que caracterizam o produto final, que podem ser inerentes a região produtiva (TRABAQUINI et al., 2019), assim como, os coeficientes técnicos de rendimento da produção e a fidelização do produtor.

Estabelecer valores para bonificação além de melhorar os resultados em qualidade, aprimoram a relação entre indústria e produtor. Isto pode ocorrer pois o sistema premeia aqueles produtores que dedicam seus esforços, empenho e seus recursos financeiros para produzirem uma matéria-prima de qualidade superior (FONSECA, 2001).

Sendo assim, um modelo de pagamento por indicadores de qualidade é a forma representativa dos valores que a empresa adotou para bonificar ou penalizar seus produtores. A definição dos indicadores para a elaboração de tal modelo de pagamento, é estabelecido a partir da legislação vigente IN 62 (BRASIL, 2011) e o histórico de produção dos produtores.

Faz-se necessário implementações efetivas de medidas que contribuam para o avanço no setor de produção de leite de qualidade, que proporcione uma maior competitividade para o setor lácteo no mercado nacional e internacional. A melhoria na qualidade depende do estabelecimento de metas apropriadas para cada contexto da produção, com respectivos registros e indicadores, com o envolvimento de todos os produtores, administradores, técnicos, indústrias, cooperativas de leite e órgãos governamentais (FARINÃ; BUSARELLO, 2013).

Um dos principais desafios está em quantificar a influência de cada parâmetro para a elaboração do Sistema de Pagamento por Qualidade (OLIVEIRA, 2012). É esta a preocupação teórica e prática que motiva esta investigação. Aliada a necessidade de contribuir para as questões comuns a esta cadeia produtiva, mas que ainda está cercada de problemas práticos.

\section{METODOLOGIA}

Trata-se de um estudo qualitativo, descritivo, com intuito de aprimoramento de ideias ou a descoberta de intuições (GIL, 2010; SAMPIERI; COLLADO; LUCIO, 2013) e a coleta de dados aconteceu por meio de entrevistas. As técnicas correspondem a análise do conteúdo (BARDIN, 2011), realizadas em diferentes formações de corpus de pesquisa formados a partir da transcrição das gravações, de acordo com cada fase do estudo.

Durante a pesquisa foi realizado a identificação dos fatores que contribuíram para a criação do Sistema de Pagamento por Qualidade, coletados por meio de pesquisa bibliográfica, entrevistas com representantes da cooperativa e produtores de leite associados para analisar o 
sistema em prática. O estudo é apresentado em três momentos distintos: primeiro foi relatado o sistema atual de pagamento por qualidade, utilizado pela organização em estudo. Em seguida, demonstrado os dados e análises da pesquisa realizada junto aos representantes da organização. Por fim, foram ouvidos e apresentados os dados coletados junto aos produtores de leite associados a cooperativa em questão.

O estudo foi desenvolvido em uma cooperativa, localizado na região Oeste do Paraná, pertencente a uma rede ligada a uma cooperativa central (optamos por não divulgar a marca), todas são focadas na agricultura familiar, do setor leiteiro. O que motivou a escolha desta organização para o estudo é o fato do modelo de gestão se repetir a toda a rede, e ter semelhanças ao dos demais modelos de gestão dos laticínios.

A cooperativa utiliza sua usina de beneficiamento para produção de leite pasteurizado e iogurte, para atender os programas governamentais: PNAE - Programa Nacional de Alimentação Escolar; PAA - Programa de Aquisição de Alimentos; Leite da Criança e o mercado regional. Como já apontado por estudos anteriores esta forma de comercialização significa explorar a potencialidade regional de alguns sistemas produtivos locais (MU et al., 2016; BREITENBACH; PARIZOTTO, 2020; VIEIRA; BASSO; KRÜGER, 2020).

Para elaboração do estudo foi realizado um censo, ou seja, incluindo no estudo, todos os casos do universo ou da população (SAMPIERI; COLLADO; LUCIO, 2013). Garantindo a conscientização e a mobilização de todos os participantes em torno do propósito da ação (GIL, 2010). As entrevistas foram realizadas com os 3 representantes da cooperativa (presidente, vicepresidente e secretário), e ainda, com os 16 produtores da agricultura familiar que fazem parte do quadro social da cooperativa e confiam a ela seu produto.

Optou-se em utilizar como instrumento para coleta de dados, entrevistas semiestruturadas, por possibilitar ao entrevistador a liberdade para desenvolver situações que agregam ao estudo, ou seja, explorar amplamente a questão (LAKATOS; MARCONI, 2011). A elaboração dos roteiros foi constituída levando em consideração o objetivo do estudo, assim como, os conceitos teóricos abordados no referencial teórico. Os roteiros bordam os temas e objetivos demonstrados no Quadro 01. 
Quadro 1 - Pressupostos dos roteiros de pesquisa

\begin{tabular}{|c|c|c|}
\hline \multirow{5}{*}{ 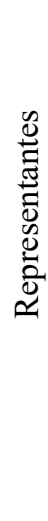 } & OBJETIVO & AUTORES \\
\hline & $\begin{array}{l}\text { Preparar ferramenta de pesquisa para compreender a organização } \\
\text { pesquisada pela lente dos entrevistados. }\end{array}$ & $\begin{array}{l}\text { Lakatos e Marconi (1992); } \\
\text { Bauer e Gaskell (2002). }\end{array}$ \\
\hline & $\begin{array}{l}\text { Comparar se os procedimentos das análises realizados pela } \\
\text { cooperativa atendem as normas apresentados no estudo. }\end{array}$ & $\begin{array}{l}\text { Brasil (2002a,b); Brasil (2011); } \\
\text { Brasil (2018a,b); Dürr (2004); } \\
\text { Santos e Fonseca (2001). }\end{array}$ \\
\hline & $\begin{array}{l}\text { Apresentar o Sistema de Pagamento por Qualidade utilizado na } \\
\text { Cooperativa e quais os parâmetros adotados. }\end{array}$ & $\begin{array}{l}\text { Ekman (2002); Embaré (2019); } \\
\text { Santos e Fonseca (2001). }\end{array}$ \\
\hline & $\begin{array}{l}\text { Compreender a percepção da Cooperativa em relação a implantação } \\
\text { do Sistema de Pagamento por Qualidade do Leite e as dificuldades } \\
\text { encontradas. }\end{array}$ & $\begin{array}{l}\text { Santos e Fonseca (2001); } \\
\text { Oliveira (2012). }\end{array}$ \\
\hline \multirow{2}{*}{ 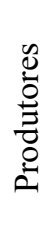 } & $\begin{array}{l}\text { Organizar as fases da pesquisa e entrevista para compreender a } \\
\text { importância da cooperativa para o entrevistado. }\end{array}$ & $\begin{array}{l}\text { Lakatos e Marconi (2011); } \\
\text { Bauer e Gaskell (2002). }\end{array}$ \\
\hline & $\begin{array}{l}\text { Comparar se os procedimentos das análises realizados pela } \\
\text { Cooperativa atendem as normas apresentados no estudo. }\end{array}$ & $\begin{array}{l}\text { Brasil (2002); Brasil (2011); } \\
\text { Brasil (2018); Dürr (2004); } \\
\text { Santos e Fonseca (2001). }\end{array}$ \\
\hline
\end{tabular}

Fonte: Dados da pesquisa (2019)

As entrevistas foram realizadas no período entre 01/10/2019 à 30/10/2019, na sede da cooperativa e nas propriedades rurais dos entrevistados. Todas as entrevistas foram gravadas e posteriormente transcritas para realização das análises. As transcrições resultaram em dois, corpus de análise (BAUER; GASKELL, 2002), ambos construídos a partir das transcrições das entrevistas, e usados para as análises de forma isolada, porém com os mesmos métodos.

A análise dos dados atendeu aos princípios da análise de conteúdo proposta por Bardin (2011) a pré-análise, a exploração do material e o tratamento dos resultados. Assim, foram definidos os processos a serem realizados: (i) as entrevistas foram transcritas na íntegra, (ii) o material passou por uma estratificação de termos similares e categorização dos resultados em classes, e (iii) a interpretação dos resultados, foi contextualizada com o referencial teórico.

Os corpora foram montados em dois arquivos com formato de txt, assim como indicado por Bauer e Gaskell (2002) e posteriormente, analisados com o apoio do Software Iramuteq 0.7 Alpha 2 (interface de R pour lês Analyses Multidimensionnelles de Testes et de Qustionnaires). O uso do software Iramutec proporcionou uma análise de conteúdo textual, que levou a um melhor conhecimento dos corpora, em seguida, aos resultados da pesquisa. Cada um dos corpora passou por suas análises com o sistema Iramuteq. Sendo rodado apenas uma vez cada, obedecendo a configuração sugerida pelo próprio sistema (REINERT, 1990). Foram utilizados para a análise de dados a Classificação Hierárquica Descendentes (CHD) e a análise de Similitude das palavras.

O software Iramutec realiza as análises fragmentando o texto do corpus, extraindo segmentos parecidos, trata-se de uma análise lexical. Isso permite visualizar o número de ocorrência de palavras, palavras distintas, número de segmentos de textos. A partir disso o próprio sistema sugere classes ou categorias que permitem uma análise do conteúdo de maneira quantificada.

DRd - Desenvolvimento Regional em debate (ISSNe 2237-9029) 
A Classificação Hierárquica Descendentes foi apresentada em gráficos de Dendrograma, que consistiu em agrupar os corpora em grupos de palavras, levando em consideração as semelhanças semânticas, propondo uma hierarquia entre as palavras no texto. Estas classes sugeridas pelo software têm origem das relações entre as palavras no texto, que será um resultado estatístico para a compreensão do corpus (MARCHAND; RATINAUD, 2012; REINERT, 1990).

A análise de Similitude das palavras gera um gráfico de rede de palavras, que mostra as relações que cada grupo de palavras possui no texto, para a escolha destes grupos é considerado a repetição das palavras, e a relação entre elas. Ou seja, palavras mais repetidas são representadas pelo tamanho da fonte na rede, e as relações pelos traçados entre as palavras (REINERT, 1990). Esta análise colabora para compreensão do corpus verificando a quantidade de repetição das palavras e suas relações entre si.

Por fim, foi realizada uma análise interpretativa dos corpora (representantes e produtores), com a Análise de Conteúdo, por concernir abordagens quantitativas e qualitativas. A análise quantitativa, por traçar uma frequência de ocorrências que se repetem no conteúdo do texto, e a qualitativa, devido ao conjunto de características em determinado segmento de texto (BARDIN, 2011), viabilizado pela utilização do software Iramuteq.

\section{RESULTADOS E DISCUSSÃO}

Os resultados são apresentados em três momentos distintos. Primeiramente, o item 4.1 apresenta o sistema de pagamento atual da empresa e o seu contexto. Na sequência são apresentados os resultados das análises com o corpus formado pelas entrevistas com os representantes. O item 4.3 apresenta os resultados do corpus dos produtores, em ambos os corpora são mostrados os gráficos de Dendograma e de Rede. Por fim, são apresentadas as discussões no item 4.4 e as considerações finais.

\subsection{SISTEMA DE PAGAMENTO POR QUALIDADE REALIZADO NA COOPERATIVA}

É importante esclarecer que o estudo foi realizado apenas em uma das cooperativas da rede, e está localizada na cidade de Cascavel-PR. Sua estrutura organizacional conta com 3 representantes, responsáveis pela gestão da cooperativa (presidente, vice-presidente e secretário) e 16 produtores da agricultura familiar que fazem parte do quadro social. As decisões mais importantes são tomadas por votação por meio da assembleia, onde todo quadro social é convidado a participar. Para compreender a relação entre a cooperativa singular e a cooperativa central: de acordo com o Representante 2: "a função da cooperativa de Cascavel é captar, produzir e fornecer o leite com qualidade para a agroindústria da nossa cooperativa central e atender também o produtor com insumos e orientação". 
Por meio dos resultados das análises realizadas no leite, a Cooperativa, além de realizar um trabalho de instrução corretiva pela médica veterinária, utiliza os resultados para mensurar o valor que será pago (bonificado ou penalizado) pela qualidade do leite produzido. A mensuração do valor repassado ao produtor, é calculado por meio de uma simulador de preços, disponível no site do Conseleite Paraná (https://conseleitepr.com.br/, 2019).

No início de 2018, quando a cooperativa passou a atender os programas governamentais, uma das exigências, é que a cooperativa deveria pagar aos seus produtores o mínimo do preço tabelado pela Conseleite. A segunda exigência era que se iniciasse o pagamento por qualidade utilizando o simulador de variação por qualidade do site da Conseleite. A partir desse momento, passou-se a pagar pelos indicadores de qualidades: gordura (\%), proteína (\%), CCS (cél/ml) e CBT (ufc/ml).

A Cooperativa tem como preço inicial, o preço base cotado pelo Conseleite, que obtém um acréscimo por cota de quantidade, mais o calculado pela variação da qualidade que pode vir a ser um ágio ou deságio no preço do leite. A cooperativa também adotou junto ao Sistema de pagamento por qualidade, uma cota de bonificação por volume produzido. Porém, ao contrário do pagamento realizado por qualidade, essa iniciativa gerou várias discussões entre o quadro de associados.

A diferença de um leite com qualidade, para um leite de qualidade inferior (comparado as mesmas condições de volume), apresenta um acréscimo considerável para o produtor. Para os representantes, é nítido que quando o produtor recebe mais, procura melhorar a produção e a qualidade do seu leite produzido. E destacam, que um dos pontos positivos, é que todo esse trabalho realizado, buscando melhorar a qualidade e bonificar por essa melhora, ajudou a cumprir as novas exigências das IN 76 e 77. Como afirma o Representante 01, "com a nova normativa, se não tivéssemos implantado o Pagamento por Qualidade a um tempo, os produtores provavelmente estariam fora do processo. [...] Todo investimento, tempo e dedicação, ajudaram a cooperativa a manter todos os seus associados".

Essa percepção também foi citada por vários dos produtores que participaram das entrevistas. Afirmando, que a cooperativa por desempenhar esse trabalho de inclusão, pagando por qualidade e disponibilizando a ajuda técnica da veterinária, ficou mais fácil adaptar-se as novas exigências. Posicionamento observado, na resposta do Produtor 5:

A nova normativa vem para ajudar e se torna justa para quem trabalha certo. A cooperativa, por exemplo, já vem desenvolvendo a muitos anos essa preocupação, disponibilizando ajuda, através da veterinária, que está a nossa disposição, e ainda bonificam quando atingirmos certos padrões de qualidade. [...] É que o trabalho da cooperativa é diferente, é de inclusão, busca ajudar, o produtor, só não evolui se não quiser.

Segundo os produtores o setor está passando por um momento de profissionalização na cadeia leiteira no Brasil. Pois, o produtor que não tiver um trabalho de inclusão, orientação, acompanhamento e incentivo será excluído, porque nenhum outro laticínio poderá comprar se o leite não tiver qualidade. Como podemos ver nesse trecho, "não existe mais o produtor mudar para outros laticínios se na análise dele não constar que o leite dele está apto para consumo. [...] Então assim, no meu ponto de vista, é um momento de profissionalismo na cadeia leiteira no Brasil" (PRODUTOR 6). 


\subsection{ANÁLISE TEXTUAL DAS ENTREVISTAS COM OS REPRESENTANTES}

O corpus das entrevistas realizadas com os representantes da cooperativa foi constituído por três textos, separados em 360 segmentos de texto (ST), com aproveitamento de 316 STs (87,78\%). Emergiram 6.945 ocorrências (palavras, formas ou vocábulos), sendo 1.319 palavras distintas e 658 com uma única ocorrência. O conteúdo analisado foi categorizado em cinco classes: Classe 1, com 81 ST (25,63\%); Classe 2, 106 ST (33,54\%); Classe 3, 48 ST (15,19\%); Classe 4, $40 \mathrm{ST},(12,66 \%)$ e Classe 5, $41(12,97 \%)$.

Esses resultados foram advindos da Classificação Hierárquica Descendente (CHD), gerando um Dendograma com as cinco classes. E a partir desse dado, foi possível a interpretação das palavras com vocabulários semelhantes entre si e as que se diferenciavam formando classes diferentes. A CHD, representada na Figura 1, favorece a visualização das principais palavras que compões cada classe construída pelo software, facilitando a interpretação dos dados.

Vale ressaltar, que essas cinco classes representadas na análise CHD do corpus dos representantes, se encontram divididas em três ramificações que serão denominadas como subcorpus (A, B e C), cuja leitura será da esquerda para direita. A Classe 5, é formadora do subcorpus A, denominado de: Importância do Sistema de Pagamento por Qualidade composto pela Classe 4. E o subcorpus B, que foi denominado de: Importância da Cooperativa. O subcorpus B irá estabelecer uma associação referente a Classe 3 e o subcorpus C, que terá o intuito de compreender a Formação de Preço (Nome dado ao subcorpus C) composto pela Classe 2 e pela Classe 1.

Quanto a denominação e interpretação das Classes, realizando uma leitura da esquerda para direita, começando a nomenclatura a partir da classe que apresenta a maior importância. A Classe 5: Sistema de Pagamento por Qualidade, refere-se à percepção que a Cooperativa obteve depois da implantação do sistema, incluindo o motivo que levou a cooperativa a implantar e os resultados observados após a implantação, que está diretamente associada à Classe 4, foi denominada de: Mercado.

Prosseguindo com a análise, a Classe 3: Assistência ao produtor, obtém os segmentos de textos que destacam a importância do trabalho de inclusão e acompanhamento técnico, visando melhorar a qualidade. Quanto a Classe 2 denominada de: Preço e a Classe 1: Comercialização do produto, estas contemplam os discursos sobre as mudanças decorrentes de todo esforço realizado, como: servir como balizadora no preço de mercado; os benefícios de atender os programas governamentais; e a dificuldades com o prazo de pagamento. A Figura 1 apresenta estas classes. 
Figura 1 - Classificação Hierárquica Descendente Corpus dos representantes

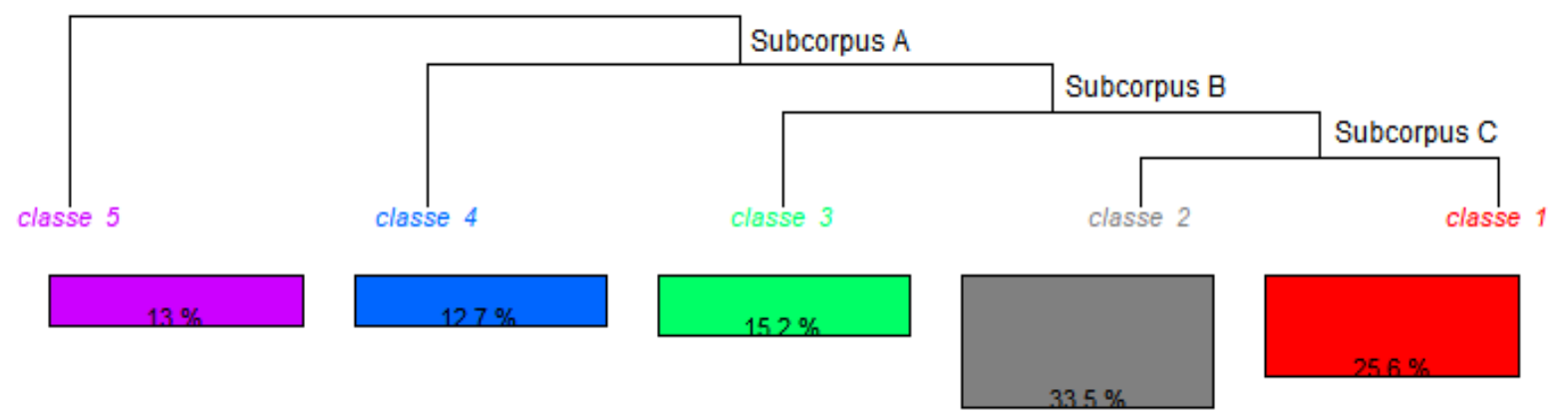

\begin{tabular}{|c|c|c|c|c|}
\hline pagamento & produto & litro & muito & porque \\
\hline sistema & nota & tirar & preço & mesmo \\
\hline implantação & fiscal & realizar & então & entrar \\
\hline indicador & cascavel & centavo & né & não \\
\hline qualidade & repassar & mensal & evoluir & entregar \\
\hline cumprir & projeto & ruim & acompanhar & dar \\
\hline programa & logurte & importância & indústria & processo \\
\hline definir & singular & retorno & $\begin{array}{l}\text { gentee } \\
\text { menos }\end{array}$ & governo \\
\hline penalizar & posicionar & mudar & lá & até \\
\hline gratificaçäo & organizar & vez & ganhar & venda \\
\hline compreender & comprar & despesa & quantidade & prazo \\
\hline 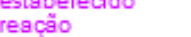 & agroindústria & cennitี & estabilizar & município \\
\hline proposto & seguimento & dívida & situaçăo & ainda \\
\hline possuir & loja & retornar & $\begin{array}{l}\text { ordenha } \\
\text { gasto }\end{array}$ & dia \\
\hline notificar & impresso & econômico & evoluçäo & assim \\
\hline $\begin{array}{l}\text { monetario } \\
\text { margem }\end{array}$ & $\begin{array}{l}\text { central } \\
\text { mercado }\end{array}$ & custo & balizador & atrasar \\
\hline gordura & pequeno & $\begin{array}{l}\text { coisa } \\
\text { coleta }\end{array}$ & $\begin{array}{l}\text { Vir } \\
\text { mundo }\end{array}$ & dentro \\
\hline $\begin{array}{l}\text { formular } \\
\text { focar }\end{array}$ & $\begin{array}{l}\text { insumo } \\
\text { certo }\end{array}$ & d_02 & propriedade & $\begin{array}{l}\text { Contar } \\
\text { problema }\end{array}$ \\
\hline $\begin{array}{l}\text { correspondente } \\
\text { apenas }\end{array}$ & $\begin{array}{l}\text { governamental } \\
\text { municipal }\end{array}$ & $\begin{array}{l}\text { análise } \\
\text { bom }\end{array}$ & $\begin{array}{l}\text { inicio } \\
\text { questäo }\end{array}$ & $\begin{array}{l}\text { vender } \\
\text { leite }\end{array}$ \\
\hline adotado & animal & $\begin{array}{l}\text { chegar } \\
\text { tabela }\end{array}$ & $\begin{array}{l}\text { Igual } \\
\text { começo }\end{array}$ & dificuldade \\
\hline $\begin{array}{l}\text { implantar } \\
\text { penslizacăo }\end{array}$ & via & como & produtor & $\begin{array}{l}\text { política } \\
\text { pagar }\end{array}$ \\
\hline ntmbalnmens & -.t.-..-1 & mensalmente & perceber & Derder \\
\hline
\end{tabular}

Fonte: Dados da pesquisa (2019)

A análise de cada classe e suas características refletidas no texto permitiu a nomenclatura das mesmas. Refletindo assim as características das falas dos entrevistados que permitiram aprofundar em cada tema encontrado. A seguir são apresentados em forma de subitens cada uma das classes, e justificado suas características e nomenclatura de acordo com as falas dos entrevistados.

\subsubsection{Classe 5: Sistema de pagamento por qualidade}

A Classe 5, Sistema de Pagamento por Qualidade, compreende 12,97\% $(f=41 \mathrm{ST})$ do corpus analisado. $\mathrm{Na}$ análise, verificou-se que apesar de apresentar a menor porcentagem de ocorrência, a classe é dominante em relação as outras, ou seja, as discussões sobre as classes Mercado, Assistência ao produtor, Preço e Comercialização do produto derivam da classe Sistema de Pagamento por Qualidade, reforçando a interpretação que o subcorpus A refere-se a Importância do Sistema de Pagamento por Qualidade. 
A categoria teve como palavras representativas: pagamento, sistema, implantação, indicador, qualidade, cumprir, gratificar e penalizar. Contribuem para essa categoria as respostas voltadas aos motivos pelo qual decidiu-se optar pela implantação do Sistema de Pagamento por Qualidade, como funciona o sistema e os resultados adquiridos. Nesta classe, pode-se verificar que o Sistema de Pagamento por Qualidade é utilizado estrategicamente, para buscar melhorar a qualidade para se tornar competitivo no mercado, como exemplifica o trecho transcrito a seguir do Representante 3:

\begin{abstract}
A decisão de se implantar um Sistema de Pagamento por Qualidade do Leite, que penalizasse por um leite ruim e gratificasse pelo leite bom. Se deu, em um primeiro momento, porque a qualidade precisava melhorar, e se não mexer no bolso do produtor ele não evolui. Então optamos por penalizar para incentivar o produtor a melhorar e bonificava para ele se sentir motivado a continuar melhorando.
\end{abstract}

\title{
4.2.2 Classe 4: Mercado
}

Essa classe representa os segmentos de texto que condiz com o posicionamento de mercado, atuação da cooperativa na sociedade, o padrão de qualidade que o consumidor espera, como podemos observar nas seguintes referências dos entrevistados: "a cooperativa tem o intuito de organizar os produtores e a forma de comercialização, agregando valor a seu produto" (REPRESENTANTE 3); ou com o trecho, "começamos com o objetivo de organizar a cadeia leiteira, a cooperativa surgiu para organizar e fortalecer o pequeno produtor, desde a qualidade a agregação de valor na transformação" (REPRESENTANTE 2).

E ainda conseguimos associar a classe Mercado com o Subcorpus A, quando analisamos o trecho: "o Sistema de Pagamento por Qualidade foi cogitado, pelo pensamento de melhorar a qualidade do nosso produto na industrialização, e também porque, a cooperativa entende que deve ser vendido um produto com qualidade de consumo, o cliente espera por isso." (REPRESENTANTE 1).

\subsubsection{Classe 3: Assistência ao produtor}

A categoria advém, do Subcorpus B, que evidência a "Importância da cooperativa". Quando analisamos o corpus na integra, e evidente o esforço da Cooperativa em dar todo apoio necessário, buscando a evolução do cooperado. Essa preocupação reflete os resultados acima, com as classes 3, 2 e 1. Para compreender a importância da "Assistência ao produtor" foram destacados os seguintes fragmentos de texto:

\footnotetext{
Esse trabalho foi bastante árduo muito investimento, análises mensais e diárias, para conseguir dar toda assistência necessária. [...] A cooperativa retorna aos produtores todas as análises, seja ela, a mensal ou as que são realizadas no momento da coleta, a veterinária já liga dando assistência em que o produtor precisa melhorar e se ele ainda tiver dificuldade, ela vai na propriedade acompanhar a produção (REPRESENTANTE 1).
} 
Realizamos reuniões periodicamente, para esclarecer qualquer dúvida do produtor e debatermos sobre todas as questões. Então sempre nos colocamos a disposição para orientá-los no que eles precisarem. Por isso que eu digo, a Cooperativa tem a obrigação de realizar um trabalho social (REPRESENTANTE 2).

\subsubsection{Classe 2: Preço}

A categoria do Preço é a mais expressiva do corpus, apresentando uma frequência de 33,5\%. As palavras mais representativas da classe foram: preço, evoluir, acompanhar, ganhar, qualidade, evolução e balizador. Essa categoria evidencia a preocupação com a Formação do preço (subcorpo C) para manter o produtor estimulado e fidelizado. Os fragmentos a seguir representam essa afirmação:

A cooperativa é um balizador de preço, por exemplo, os produtores em geral vem até a cooperativa para especular o preço que estamos pagando aos nossos produtores, ai ele vai até o laticínio e briga por um preço melhor, se eles não pagarem, ele ameaça se juntar a nossa Cooperativa. Sem falar, que como somos um grupo organizado ajudamos a cadeia leiteira (REPRESENTANTE 1).

Cooperativa surgiu através de uma demanda de sócios que estavam recebendo um preço muito baixo, praticado na região. Como é pequeno produtor, ele não tinha muito volume e os grandes laticínios exploravam essa questão. Então, a Cooperativa surgiu para estabilizar o preço na região, e hoje os laticínios tiveram que pagar a mesma coisa, e assim, pararam de sugar o produtor (REPRESENTANTE 2).

Produtor que tem bons números de qualidade, ele está ganhando em preço, ganhando mais na produção ele tem um retorno maior. E se ele tem uma qualidade boa quer dizer, que ele também, reduziu o custo com medicamentos, com perca com animal e de produção (REPRESENTE 3).

\subsubsection{Classe 1: Comercialização do produto}

Segunda maior categoria, a Comercialização do produto também é muito expressiva. Isso se deve ao fato da classificação das palavras estár ligada ao subcorpo $\mathrm{C}$, mantendo a preocupação com a Formação de preço. Nessa categoria, aparece a preocupação com o tempo de recebimento, já que a maior parte da sua produção é comercializada para programas governamentais e por mais que a venda seja garantida, há um atraso na hora de receber, dificultando o repasse para os produtores. Afirmação que é justificada nos seguintes fragmentos:

Entregamos a maior parte da nossa produção para órgãos governamentais e temos problemas com data de pagamento... (REPRESENTANTE 3).

Quando começamos a pagar por qualidade ganhamos em qualidade no produto comercializado. Assim, conseguimos adequar a produção para entregar a programas 
governamentais, o que é confortável por ser uma venda garantida, o problema é que sempre atrasa o pagamento (REPRESENTANTE 1).

Outra preocupação que temos, é que como nossa comercialização está voltada uns $90 \%$ para programas governamentais, eles são vulneráveis. Hoje pode existir e amanhã podem ser cancelados. Então, uma de nossas preocupações está em aumentar nosso segmento de mercado (REPRESENTANTE 2).

Após a análise da CHD é importante verificar se houve coerência nas interpretações realizadas com os dados obtidos em cada Classe. Para isso, será utilizado outro método disponibilizado pelo software Iramuteq, a análise de Similitude. Essa análise permite a visualização das conexões entre os termos mais relevantes e suas ramificações com as palavras que estão em um mesmo contexto. Dessa forma foi possível averiguar se as contextualizações de cada Classe apresentada anteriormente são consistentes.

4.2.6 Análise de Similitude do corpus associado aos representantes

A análise de Similitude, possibilita a identificação das ocorrências entre as palavras, a força de associação entre os termos através de suas conexões, auxiliando na identificação da representação da estrutura e na interpretação dos resultados (MARCHAND; RATINAUD, 2012).

Na Figura 2 observa-se que as palavras que ocorreram com mais frequência, foram: cooperativa, produtor, qualidade, leite e com menos ocorrência mais ainda em destaque, o pagamento. Após realizada essa análise genérica, pode-se considerar a força entre as conexões e os segmentos de ramificações. 
Figura 2 - Análise de Similitude - Corpus Representantes

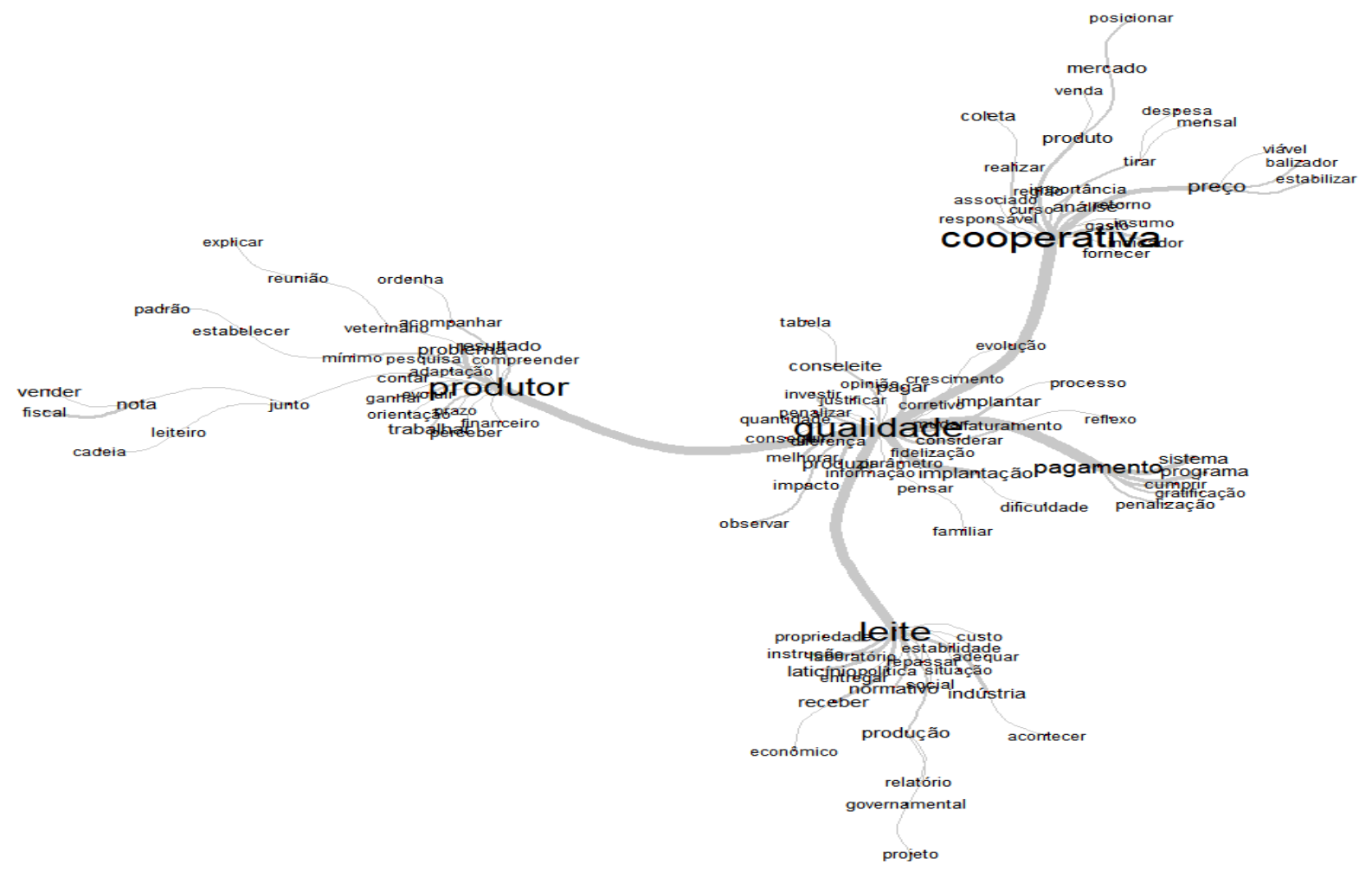

Fonte: Dados da pesquisa (2019)

Podemos observar que as palavras: cooperativa, produtor, leite e pagamento, apresentam uma forte conexão com a palavra qualidade, apresentada bem ao centro da árvore de similitude. Pode-se considera por meio dessas conexões, que "a qualidade do leite é fundamental para se manter no mercado, e é por esse motivo, que a cooperativa decidiu implantar um sistema de pagamento para incentivar o produtor a melhorar" (REPRESENTANTE 1).

Analisando cada palavra de maior frequência isoladamente, apenas com suas ramificações próximas, contemplam os mesmos resultados encontrados na análise CHD. Como, por exemplo, a qualidade, aparece centralmente ramificando com o termo pagamento, que quando analisamos a CHD, destacou-se como a Classe 5 - Sistema de Pagamento por Qualidade, que gerou o subcorpus A, Importância do Sistema de Pagamento, evidenciada em fragmentos de texto, que correspondem a importância da qualidade e os métodos para se obter uma boa qualidade, associadas a Classe 4 - Mercado.

Quando isolamos as palavras produtor e leite, observamos a associação com o subcorpus B, Importância da cooperativa, que vai tratar principalmente da Classe 3 - Assistência ao produtor e a preocupação da cooperativa com seu quadro social e assistência realizada para alcançar um leite de melhor qualidade na indústria.

E finalizando, observamos a palavra cooperativa, em uma posição superior as outras. Está associada a palavras como: preço, estabilizar, mercado, importância, associado e mercado, compreendido nas análises do subcorpus C, Formação de Preço e suas respectivas classes Preço e Comercialização do produto. Evidenciando aos motivos que se optou em implantar um 
programa de qualidade, de fundar uma cooperativa e sua preocupação com a comercialização atual. Denotando a consistência entre os resultados obtidos.

\subsection{ANÁLISE TEXTUAL DAS ENTREVISTAS COM OS PRODUTORES}

O corpus formado pelas entrevistas com os produtores da agricultura familiar foi constituído por dezesseis textos, separados em 692 segmentos de texto (ST), com aproveitamento de 493 STs $(71,24 \%)$. Emergiram 24.651 ocorrências (palavras, formas ou vocábulos), sendo 2.255 palavras distintas e 1.079 como uma única ocorrência. O conteúdo analisado foi categorizado em quatro classes: Classe 1, com 198 ST (40,16\%); Classe 2, 118 ST (23,94\%); Classe 3, 103 ST (20,89\%) e Classe 4, 74 ST (15,01\%).

Os resultados adquiridos por meio da Classificação Hierárquica Descendente (CHD), gerou um dendograma com quatro classes, representadas na Ilustração 8. As classes estão divididas em duas ramificações, denominadas como subcorpus (A e B), cuja leituras subcorpus será da direita para esquerda. Sendo assim, a Classe 4 é responsável pela formação do subcorpus A, que foi denominado de: Iniciativas que contribuem para o desenvolvimento do cooperado, composta pelas Classe 3 e o subcorpus B, que foi denominado de: Fortalecimento do pequeno produtor, que por sua vez é formado pelas Classe 1 e pela Classe 2.

Quanto a denominação e interpretação das Classes, a leitura será por grau de importância e é representada de forma dinâmica na Figura 3. A classe que apresentou maior importância é a Classe 4, denominada de: Importância da Cooperativa na Agricultura Familiar, refere-se à importância que os produtores empregam a participar de uma Cooperativa da Agricultura Familiar de uma forma voltada ao mercado. A segunda classe de maior grau de importância é a Classe 3, que foi chamada de: Sistema de Pagamento por Qualidade, que destaca a percepção que os produtores têm, sobre o Sistema de Pagamento ser pago por indicadores de qualidade. Quanto a Classe 2: Gestão da Produção e a Classe 1: Importância de ser um cooperado, elas contemplam fragmentos das entrevistas, relacionados aos auxílios que os produtores recebem da Cooperativa, promovendo sua evolução como cooperado. 
Figura 3 - Classificação Hierárquica Descendente Corpus dos produtores

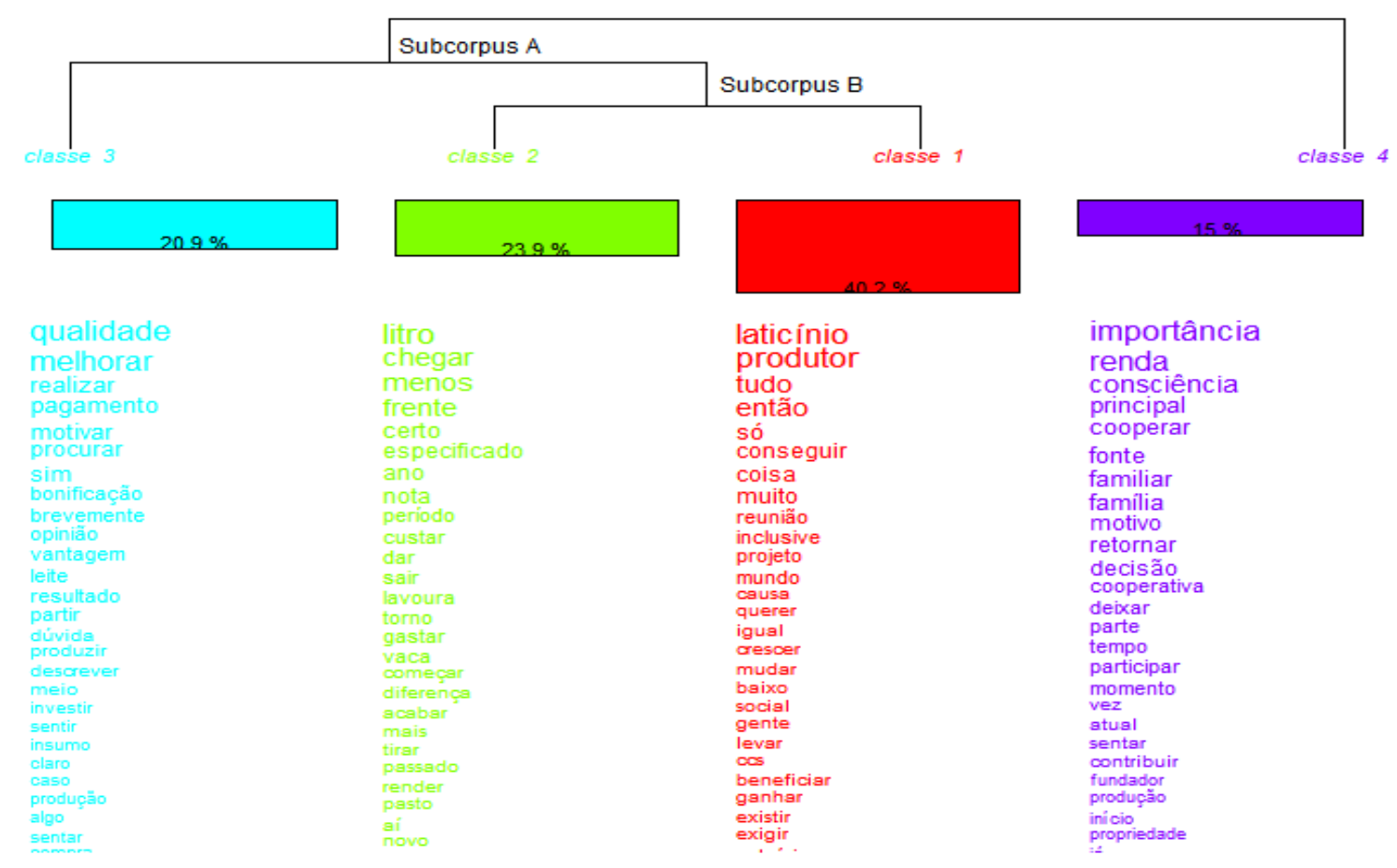

Fonte: Dados da pesquisa (2019)

Para adentrar na interpretação detalhada de cada classe, serão selecionados apenas os fragmentos de texto dos produtores que compõe sua classe. A seguir os subitens apresentam cada uma das classes e justificam a nomenclatura dada a cada uma delas com as próprias falas dos entrevistados.

\subsubsection{Classe 4: Importância da Cooperativa na Agricultura Familiar}

A categoria Importância da Cooperativa na Agricultura Familiar, foi a classe de menor expressão, porém ela apresenta o maior grau de importância no CHD, pois está associada aos fragmentos de resposta de todas as classes. As palavras mais representativas da classe, foram: importância, renda, consciência, principal, cooperar entre outros. Nessa classe, contempla a importância da produção de leite, por ser a principal fonte de renda de todos os cooperados, e é um dos principais motivos da Cooperativa ser tão importante para os produtores.

Para maioria dos produtores, a Cooperativa é importante porque realiza um trabalho social, fornecendo assistência e auxiliando os produtores (afirmação que também será tratado na Classe 1, Importância em ser um Cooperado). Além, de impedir que o pequeno produtor seja explorado por laticínios maiores, por não obterem um volume considerável de produção, retratado na afirmação do Produtor 4: “...a Cooperativa agrega mais, ajuda a agregar mais valor, além de ter uma inclusão um trabalho mais social, de acompanhamento e orientação". 
Porém, foi possível identificar durante as entrevistas que para alguns produtores estão associados apenas para entregar seu leite, não tem nenhuma intenção de participar ativamente da Cooperativa. Para estes o motivo de permanecer na Cooperativa é por possuírem baixo volume de produção, e em um laticínio maior não conseguiriam brigar por um preço melhor. Para retratar as duas afirmações acima, foram separados alguns fragmentos que representa a Classe:

A cooperativa é muito importante para a gente, sem ela estaríamos sendo explorados como antes. [...] Os laticínios pagavam quanto eles queriam, isso quando eles aceitavam pegar o leite da gente, diziam que era pouquinho e que não compensava o frete (PRODUTOR 12).

Mas infelizmente, o povo não é cooperativista, o povo é individualista, nós estamos em um mundo capitalista é uma questão difícil de mudar. Muitos só pensam em vender e não pensam que pode vir um projeto e ajudar todo mundo junto, eles não entendem que eles são pequeno e só vão crescer se unindo (PRODUTOR 13).

A cooperativa ela dá segurança pra nós produtores na questão da comercialização e na busca da agregação de valor. Sempre foi, desde o início da cooperativa, a discussão principal é ter uma industrialização para agregar mais valor ao nosso produtor (PRODUTOR 4).

A seguir, apresentam-se os fragmentos de texto, dos produtores que não fazem parte da formação da classe, porém apresentam uma opinião contrária sobre a importância em participar da Cooperativa:

Pra gente, não tem importância nenhuma a Cooperativa. Tanto faz o lugar que a gente for entregar, porque nós não participamos, assim, diretamente sabe, só entregamos o leite mesmo (PRODUTOR 10)

Eu acho que a Cooperativa não tem importância nenhuma. A gente até já tinha saído uma vez, só retornou por causa do preço, porque o preço se tornou melhor que os ostros laticínios (PRODUTOR 14).

\subsubsection{Classe 3: Sistema de Pagamento por Qualidade}

A categoria Sistema de Pagamento por Qualidade, deriva de um subcorpus A, que demonstra ao cooperado, as iniciativas que a Cooperativa realiza para contribuir com o seu desenvolvimento. Nessa classe, surgem debates sobre a motivação, as vantagens, sobre a penalização, e outras questões relevantes ao estudo como, por exemplo, o fato de o Sistema de Pagamento por Qualidade ter ajudado os produtores a se adaptarem as novas normativas. Analisando o corpus é evidente a aceitação dos produtores sobre o pagamento ser realizado sobre indicadores de qualidade. Como afirmam os produtores a seguir:

O pagamento por qualidade, foi o caminho que a cooperativa encontrou para melhorar a qualidade e o produto da indústria, porque de certa forma, foi um jeito que obrigou os produtores, por que quem que não vai querer ganhar mais? Então assim, muitos realmente melhoraram bastante a qualidade por causa desse pagamento a mais (PRODUTOR 6) 
Sim recebemos bonificações, sobre os resultados das nossas análises. [...] O bom de receber por qualidade é que, mesmo com pouca litragem, eu posso receber um preço melhor pelo meu leite, e ainda me ajuda a prevenir vários tipos de doenças na propriedade. (PRODUTOR 15).

Eu que ser penalizado é sempre ruim financeiramente, porque a gente conta com aquele pouquinho, mas assim, a gente entende que se o leite tiver ruim é falha minha, e a gente não pode prejudicar os outros produtores com um leite que não está bom, então a gente tem que ser responsabilizado. [...] Ainda mais agora que temos que cumprir à risca a nova normativa né, até quem estava empurrando com a barriga até agora, não vai poder mais, ou melhora ou sai fora né (PRODUTOR 16).

No entanto, o Produtor 11 demostrou uma opinião contrária sobre a Cooperativa pagar por qualidade, e explicou o motivo que o faz acreditar que não recebe por qualidade. Porém, ele demostra uma opinião favorável em relação ao pagamento ser realizado por qualidade, assim como ele relata a seguir:

No recibo pelo menos, não vem nada, por isso, bato na tecla que não recebo por qualidade. Por que você não concorda comigo, que se eles pagassem tinha que vir no recibo? Como vou saber se recebo, se não está no recibo? Porque se diz que paga por qualidade tem que especificar. [...] Porém, se realmente tivesse uma bonificação é claro que eu gostaria de receber, é meu esforço recompensado. E quanto a penalização, se eu tiver penalização é porque eu estou errado, não é verdade, claro que tem que ter a penalização, pra se tornar justo com as pessoas que produzem leite de qualidade e que procuram melhorar. E se tiver bonificação a gente trabalha até mais motivado, claro, claro, e se o produtor não estiver dentro das normas tem que ser penalizado eu concordo.

\subsubsection{Classe 2: Gestão da Produção}

A categoria Gestão de Produção está vincula a Classe Importância em ser um Cooperado no que se refere a diminuição nos custos de produção através dos benefícios em participar do quadro social de uma Cooperativa da agricultura Familiar. No entanto, a Classe em questão evidência a dificuldade que o produtor tem em fazer o controle de custos de sua produção. Afirmação que é compartilhada por todos os produtores, já que nenhum faz o controle efetivo dos gastos com a produção.

Os produtores que conseguem ter uma ideia vaga, sobre o custo de sua produção, é porque realizam as compras dos insumos na loja da própria Cooperativa. Que por sua vez, repassa ao produtor uma nota de quanto ele gastou com a compra de insumos e o valor que ele recebeu por sua produção, facilitando o controle ao produtor. A seguir alguns fragmentos de texto selecionados sobre a classe Gestão da Produção:

Uma vez eu fazia o controle da produção e sabia certinho quando eu gastava pra produzir um litro, mas agora não faço mais não, a gente só fica preocupado em produzir mesmo. Mas esses dias eu peguei as notas da Cooperativa, porque lá eu tenho o quanto gastei com ração e medicamentos e quanto recebi, então mais ou menos, $60 \%$ do valor que eu recebo é custo (PRODUTOR 2). 
Assim que eu entrei na Cooperativa fui beneficiado com calcário, e isso me ajudou a economizar e pagar um pouco o que eu investi na minha produção. [...] Olha não faço ideia de quanto custa o litro de leite na minha produção, mas acredito que hoje está custando entorno de $60 \%$ do que eu recebo. [...] Eu procuro dar preferência em comprar na loja da Cooperativa, assim eu ajudo a Cooperativa a gerar receita e eu consigo controlar melhor meus gastos, porque é mais fácil quando a gente pega e recebe do mesmo lugar (PRODUTOR 7).

\subsubsection{Classe 1: Importância de ser um Cooperado}

Essa é a categoria que apresenta a maior relevância para os produtores, pois está associada os benefícios que eles recebem por participar do quadro social. Os assuntos mais relevantes abordados nessa classe, são: os projetos a fundo perdido, que por meio deles, os cooperados conseguem auxílio de maquinários e insumos, diminuindo custo de produção; outro ponto em destaque, é a participação nas decisões da Cooperativa e os auxílios com formação, orientação e acompanhamento. Porém os produtores admitem que nem todos os cooperados participam ativamente da Cooperativa, essas afirmações estão retratadas a seguir:

A importância pra nós, está relacionado em ser um Cooperado, por termos liberdade, não digo para discutir preço, mas para darmos nossa opinião e participarmos das decisões. Além de a gente ser beneficiado com os projetos, não só como Cooperativa em si como CNPJ, mas também o quadro social. [...] A Cooperativa faz muito trabalho social, ajuda a gente com formação, orientação e prevenção. Temos auxilio da veterinária que acompanha a produção. [...] Então, o que ajuda muito a gente, é a Cooperativa pagar por qualidade, além de ajudar o produtor a se enquadrar em questão de qualidade, realmente esse pagamento a mais faz a diferença (PRODUTOR 1).

Infelizmente temos na Cooperativa alguns cooperados que não entendem o significado de Cooperativismo, eles acham que é entregar leite, mas nós através da Cooperativa tivemos várias conquistas, com projetos, um monte de coisa para indústria, olha quanta coisa conseguimos lá naquela indústria, e sem a Cooperativa a gente não conseguiria (PRODUTOR 3).

\subsubsection{Análise de Similitude do corpus associado aos produtores}

A análise de similitude (Figura 4) reforça as afirmações e preocupações encontradas na análise da CHD. A árvore de similitude, tem como principal frequência a palavra cooperativa e suas ramificações secundárias. Nesse grupo de palavras, é evidente seguindo as conexões de palavras, a consciência dos cooperados sobre a importância da cooperativa, os benefícios por ser parte do quadro social e a orientação que eles recebem para conseguir entregar um produto de qualidade e atender as exigências das normativas, afirmações contempladas na Classe 5 e Classe 1. 
Figura 4 - Análise de Similitude - Corpus Produtores

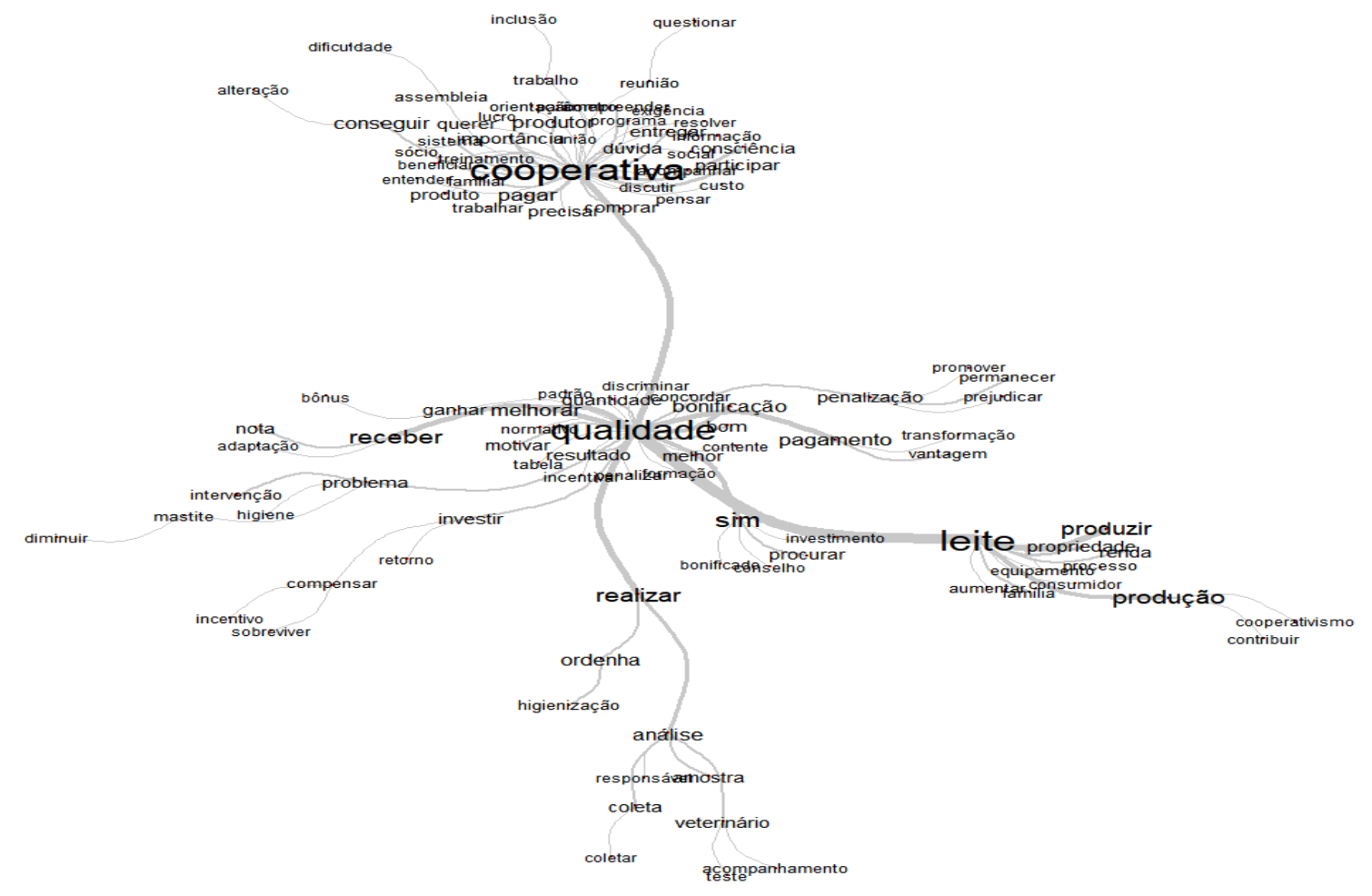

Fonte: Dados da pesquisa (2019)

A palavra qualidade, disposta no centro da árvore de similitude, apresenta uma conexão mais forte com a palavra leite. Essa conexão, denota a preocupação que os produtores estão tendo com a qualidade do seu leite. Principalmente agora, com as novas normativas, como afirma o Produtor 16, "ainda mais agora que temos que cumprir à risca a nova normativa, quem estava empurrando com a barriga até agora, não vai poder mais, ou melhora a qualidade do leite, ou sai fora".

Analisando a palavra qualidade isoladamente, apenas com as suas conexões mais próximas, temos palavras como: bonificação, contente, melhor, formação, incentivar, resultado, motivar, melhorar e ganhar. Essas palavras, compões principalmente os fragmentos encontrados na Classe 4, Sistema de Pagamento por Qualidade. A maioria dos entrevistados, afirmam que se sentem motivados, contentes e incentivados, pelas bonificações a buscar melhores resultados em qualidade para poder ganhar mais.

A árvore de similitude, obtém informações relevantes quando analisamos as conexões menores: i) receber a qualidade na nota; ii) quando há um problema de qualidade é realizado uma intervenção; iii) o investimento depende do retorno e dos incentivos, pois com a política atual está dando só para sobreviver; iv) é realizado um acompanhamento feito pela veterinária, que é responsável pela coleta das amostras; v) os produtores procuram investir para aumentar sua produção e contribuir com a cooperativa e vi) o pagamento por qualidade é uma vantagem e uma transformação da cadeia, e mesmo com as penalizações, por mais que o produtor se sinta prejudicado financeiramente, incentiva ele a melhorar. 
Os fragmentos de textos apresentados na análise anterior, foram retirados das respostas dos 16 produtores entrevistados. E importante destacar que as afirmações foram compiladas, considerando maiores frequências e em um mesmo contexto. Os produtores que apresentaram opiniões contrárias a maioria estão representados na interpretação de cada classe. Pelas análises de similitude e da CHD, verificamos a consistência dos resultados apresentados.

\subsection{DISCUSSÕES DOS RESULTADOS}

Após a análise dos dados apresentados ao transcorrer desta pesquisa pode-se destacar alguns pontos relevantes observados durante a elaboração do estudo. Primeiramente, é importante destacar os motivos que implicaram para adoção de um Sistema de Pagamento por Qualidade na Cooperativa, segundo os representantes, essa iniciativa foi necessária para melhorar a qualidade dos seus produtos. Para Silva e Liserre (2009), a prática de melhorar o preço pago aos produtores, por meio de benefícios ou remuneração por indicadores de qualidade, tornou-se fundamental para incentivar a melhoria na qualidade.

Segundo os representantes e produtores, não houve dificuldades de implantação e aceitação dos produtores, pois a adaptação aconteceu de forma gradual, ou seja, a diferença repassada em bonificações/penalizações por qualidade a princípio era baixa. Quando a Cooperativa passou a atender a demanda do programa Leite das Crianças, uma das regras que o programa estabelecia era a utilização de um simulador de variação do pagamento por qualidade disponível no site Conseleite. Esse simulador tem como objetivo remunerar por meio de bonificação/penalizações os indicadores: gordura, proteína, CBT e CCS. A partir desse momento, os resultados na diferença no pagamento passaram a ser significativos e a qualidade do leite produzido melhorou, atingindo o objetivo proposto na implantação.

O Sistema de Pagamento por Qualidade adotado na Cooperativa, prevê bonificação e penalização. Porém é importante lembrar que segundo Oliveira (2012), no que se refere a penalização, essa iniciativa pode ser inviável para algumas indústrias, já que os produtores podem migrar para um laticínio que não penalizam por indicadores de qualidade. Dessa forma, utilizar a estratégia de penalização por qualidade pode ser um risco no que tange a fidelização (POPESCU; ANGEL, 2019).

No entanto, os produtores que participam da Cooperativa, admitem que há sim um prejuízo financeiro, mas que compreendem a necessidade da responsabilização. Essa afirmação foi justificada, que por se tratar de uma Cooperativa da agricultura familiar, não seria justo outros cooperados arcarem por um leite fora do padrão, e relatam que essa iniciativa incentiva a busca pela melhoria na qualidade, para que não ocorra uma segunda penalização. A única ressalva negativa que fizeram sobre o pagamento por qualidade, está associado ao fato de a Cooperativa não emitir em nota fiscal o valor bonificado/penalizado sobre a variação da qualidade do leite, o que faz com que alguns produtores não acreditem na efetividade do pagamento.

Avaliando o Sistema de Pagamento por Qualidade, por uma perspectiva econômica, comprovou-se que o produtor que obtém um leite de boa qualidade consegue ganhar consideravelmente a mais, que o produtor que possui resultados baixos nos indicadores de 
qualidade, confirmando o fator motivador. Essa valorização foi definida pelos produtores, como recompensa pelo esforço realizado para melhorar a qualidade da sua produção, e que vem sendo um estímulo para permanecer no setor.

Estabelecer valores de bonificação, além de melhorar os indicadores de qualidade, aprimoram o relacionamento entre indústria e produtor, pois premiam aqueles que dedicam seus esforços para produzirem um leite de melhor qualidade (FONSECA, 2011; POPESCU; ANGEL, 2019). Os representas compreendem a importância de um pagamento por qualidade, pois a Cooperativa não só obteve resultados positivo em melhora na qualidade, como também, ajudou na evolução e desenvolvimento dos seus cooperados, e consequentemente a Cooperativa se desenvolve junto.

Muitos produtores, afirmam que realmente investem em melhorias para garantir a qualidade e o aumento da sua produção. Porém, alguns produtores ainda não se sentem confortáveis em investir em suas produções, esse fato está associado a falta de valorização e as dificuldades apresentadas no setor lácteo. Os produtores reconhecem o esforço e o trabalho social realizado pela Cooperativa, no entanto, não estão contentes com o setor, que não está repassando um preço base condizente com as exigências realizadas.

Outro ponto destacado nas entrevistas (representantes e produtores), é a dificuldade em fidelizar produtores com um volume maior de produção, posto que, esse produtor acaba entregando sua produção para quem paga mais. Por esse motivo, a Cooperativa adotou a estratégia de pagar uma cota por volume, além da qualidade, para tornar seu preço mais atrativo. No entanto, por se tratar de uma Cooperativa da agricultura familiar, alguns produtores não são adeptos dessa ideia, defendendo que esse tipo de sistema gera desigualdade e vai contra aos princípios da Cooperativa de crescer de forma unida.

É importante destacar, que em referência a literatura, os planos para incentivar e reter produtores, são definidos de acordo com a necessidade da produção e objetivos da indústria. A indústria deve avaliar quais indicadores geram mais benefícios e rendimentos de produção ao seu produto, bem como, a necessidade de uma estratégia para fidelização. Sendo assim, cabe a indústria implantar o sistema de pagamento que melhor atenda suas necessidades (BARROS et al., 2000).

No quesito, análise e acompanhamento da qualidade, a Cooperativa desempenha um trabalho de acordo com os especificados nas IN 76 e 77. A coleta é realizada por uma veterinária especializada, em um período mensal. Outro controle realizado é o teste com Alizarol em cada coleta, que indicará o nível acidez, que tem objetivo de indicar o estado de conservação do leite. As análises são envidas aos laboratórios credenciados pela RBQL que emite o retorno das análises a Cooperativa, que por sua vez, repassa ao seu produtor realizando intervenções caso necessário, procedimentos exigidos pelas normativa (BRASIL, 2018a, b).

A Cooperativa realiza um trabalho árduo, reconhecido pelos produtores, que recebem assistência técnica para melhorar a qualidade de sua produção. Segundo os cooperados esse trabalho associado ao Sistema de Pagamento por Qualidade, contribui positivamente para que a transição para as novas exigências (IN 76 e 77) acontecesse de maneira orgânica. Essas iniciativas ajudaram a Cooperativa a permanecer com sua produção habitual, tendo em vista, que uma das novas exigências é o cancelamento da coleta do produtor que não apresentar uma média trimestral de CPP (ou CBT) dentro dos padrões (BRASIL, 2018a, b). 
Uma das principais dificuldades, também destacada pelos produtores, está no controle da qualidade associada ao indicador CCS, presença de infecções ou mastite no rebanho, já que seus sintomas são imperceptíveis visivelmente (MACHADO; PEREIRA; SARRIÉS, 1999). Contudo, vale ressaltar, que caso o CCS não esteja nos parâmetros estabelecidos na IN 76, não gerará a interrupção da coleta. O produtor só sofrera essa penalização caso apresente o CPP fora do padrão exigido (PARANHOS, 2019). Para os produtores entrevistados, as novas normativas vêm para contribuir com profissionalismo no setor, tornando-se justa para quem trabalha atendendo todas as especificações, como no caso da Cooperativa.

Com intuito de esclarecer os resultados da pesquisa e os principais impactos observados ocasionados pela implantação de um Sistema de Pagamento por Qualidade elaborou-se um quadro com os principais impactos obtidos em cada Classe do dendograma da análise CHD para facilitar a compreensão (Quadro 2). Contudo, vale lembrar, que esses impactos foram percebidos nesta Cooperativa, ou seja, os impactos podem ser diferentes em outros casos de indústrias que optaram pela implantação de um Sistema de Pagamento por Qualidade. 
Quadro 2 - Principais impactos obtidos pela da análise CHD

\begin{tabular}{|c|c|c|}
\hline Classes & \multicolumn{2}{|c|}{ Principais impactos } \\
\hline \multicolumn{3}{|l|}{ Corpus Representantes } \\
\hline & Impactos Positivos: & Impactos Negativos: \\
\hline $\begin{array}{l}\text { Classe 5: Sistema de } \\
\text { Pagamento por Qualidade }\end{array}$ & $\begin{array}{l}\text { - Melhoria na qualidade do produto final; } \\
\text { - Contribui para a evolução do cooperado; } \\
\text { - Aumentou a renda da Cooperativa } \\
\text { (programas governamentais); } \\
\text { - Motivação do produtor; } \\
\text { - Redução de perdas e custo; } \\
\text { - Segurança alimentar para consumidor. }\end{array}$ & $\begin{array}{l}\text { - A Classe não presentou menção a } \\
\text { impactos negativos. }\end{array}$ \\
\hline Classe 4: Mercado & $\begin{array}{l}\text { - Fortaleceu o pequeno produtor; } \\
\text { - Organizou a cadeia produtiva da região; } \\
\text { - Agregou valor a produção; } \\
\text { - Balizadora de Preço. }\end{array}$ & - Dificuldade de fidelização. \\
\hline $\begin{array}{l}\text { Classe 3: Assistência ao } \\
\text { Produtor }\end{array}$ & $\begin{array}{l}\text { - Trabalho social; } \\
\text { - Projetos de incentivos; } \\
\text { - Melhora da qualidade; } \\
\text { - Profissionalismo do cooperado; } \\
\text { - Melhores práticas. }\end{array}$ & $\begin{array}{l}\text { - A Classe não presentou menção a } \\
\text { impactos negativos. }\end{array}$ \\
\hline Classe 2: Preço & $\begin{array}{l}\text { - Balizador o preço na região; } \\
\text { - Agregação de valor; } \\
\text { - Fim da exploração do pequeno produtor. }\end{array}$ & $\begin{array}{l}\text { - A Classe não presentou menção a } \\
\text { impactos negativos. }\end{array}$ \\
\hline $\begin{array}{l}\text { Classe 1: } \\
\text { Comercialização do } \\
\text { produto }\end{array}$ & -Venda garantida. & $\begin{array}{l}\text { - Dificuldade no pagamento dos } \\
\text { produtores. }\end{array}$ \\
\hline \multicolumn{3}{|l|}{ Corpus Produtores } \\
\hline \multirow[b]{2}{*}{$\begin{array}{l}\text { Classe 4: Importância da } \\
\text { Cooperativa na } \\
\text { Agricultura Familiar }\end{array}$} & Impactos Positivos: & Impactos Negativos: \\
\hline & $\begin{array}{l}\text { - Fim da exploração do pequeno produtor; } \\
\text { - Valorização da produção; } \\
\text { - Segurança ao produtor; } \\
\text { - Representação dos pequenos produtores; } \\
\text { - Benefícios por meio de projetos. }\end{array}$ & $\begin{array}{l}\text {-Falta de compreensão sobre o } \\
\text { Cooperativismo. }\end{array}$ \\
\hline $\begin{array}{l}\text { Classe 3: Sistema de } \\
\text { Pagamento por Qualidade }\end{array}$ & $\begin{array}{l}\text {-Aumentou a renda familiar; } \\
\text {-Incentivo a permanecer no setor; } \\
\text {-Incentivo a melhorar; } \\
\text {-Investimentos em qualidade; } \\
\text {-Reconhecimento do produtor. }\end{array}$ & $\begin{array}{l}\text { - Descrença do produtor quanto a } \\
\text { efetividade do pagamento; } \\
\text { - Descontentamento ocasionado } \\
\text { pela associação do pagamento por } \\
\text { cota de quantidade. }\end{array}$ \\
\hline $\begin{array}{l}\text { Classe 2: Gestão da } \\
\text { Produção }\end{array}$ & -Redução de custos por meio de projetos. & $\begin{array}{l}\text {-Falta de controle dos custos da } \\
\text { produção. }\end{array}$ \\
\hline $\begin{array}{l}\text { Classe 1: Importância de } \\
\text { ser um Cooperado }\end{array}$ & $\begin{array}{l}\text { - Proximidade com a cooperativa; } \\
\text { - Poder de decisão; } \\
\text { - Receber benefícios com os projetos } \\
\text { sociais; } \\
\text {-Auxílio técnico; } \\
\text {-Evolução profissional. }\end{array}$ & $\begin{array}{l}\text { - A Classe não apresentou menção } \\
\text { a impactos negativos. }\end{array}$ \\
\hline
\end{tabular}

Fonte: Dados da pesquisa (2019)

Como sugestão para promover o desenvolvimento da Cooperativa, procurando manter e melhorar os impactos positivos recomenda-se aos representantes a elaboração de Plano de melhoria contínua. Segundo Slack, Chambers e Johnson (1997) não importa o quão bem gerenciada é uma operação, ela sempre é passível de melhoramento, porém, é necessário que haja uma medida de desempenho. Assim, a Cooperativa pode estabelecer seus objetivos, 
adequar a estratégias e acompanhar seus resultados, dessa maneira, ela buscará o desenvolvimento contínuo, se mantendo competitiva no mercado.

No que tange aos impactos negativos as sugestões de melhorias serão fornecidas pontualmente, visando auxiliar a Cooperativa a reverter tais impactos, sendo assim: (i) quanto a fidelização, é necessário a elaboração de um plano de incentivo (premiação, confraternizações) e um acompanhamento mais próximo ao produtor, para reconhecer a importância do seu cooperado e despertar o senso de coletivo; (ii) o pagamento por cota de quantidade é um dos assuntos mais delicados na Cooperativa, pois divide opiniões. Precisa ser convocado uma nova assembleia e esclarecer os motivos estratégicos que levaram a essa decisão, caso permaneça a insatisfação, a Cooperativa precisará fazer uma reavaliação dos prós e contras para tomar uma decisão para que não a prejudique no futuro.

No que se refere ao atraso do pagamento (iii), a Cooperativa precisa aumentar seu segmento do mercado, lançando um produto assertivo para um novo tipo de cliente, dessa forma obterá um capital de giro para arcar com os pagamentos e não dependerá só dos programas governamentais. Para solucionar a descrença sobre o pagamento ser realizado por qualidade (iv), basta inserir a informação em nota e (v) dado que o produtor não realiza a gestão de sua produção, a Cooperativa pode buscar parcerias com instituições para promover aos seus cooperados um curso de gestão financeira. No entanto, não garante a solução efetiva, já que a gestão de custo é algo de interesse do próprio produtor. É importante salientar que as sugestões são recomendações, e por tanto, precisam ser avaliadas perante a realidade da empresa.

As contribuições dessa pesquisa estão voltadas, principalmente, aos representantes da Cooperativa, que neste estudo podem compreender a percepção dos seus cooperados, os impactos gerados pela implantação de um Sistema de Pagamento por Qualidade e a importância da Cooperativa na agricultura familiar. No que se refere aos cooperados, a pesquisa pretende ajudar ainda mais, estabelecendo o relacionamento entre cooperativa e cooperado. Por fim, é importante destacar, o posicionamento de alguns produtores em relação a cooperativismo, indicando a necessidade de um trabalho mais próximo da Cooperativa nesses casos isolados, para que todos possam ter a oportunidade de evoluir juntos.

\section{CONSIDERAÇÕES FINAIS}

A qualidade do leite cru, é fundamental para as indústrias se manterem competitivas no mercado. Com um consumidor cada vez mais exigente e uma legislação cada vez mais preocupada em garantir a inocuidade do produto final. As indústrias passaram a procurar meios de incentivar seus produtores a investirem em sua produção, e sendo assim, o pagamento pela qualidade se tornou o modelo mais aceito na cadeia produtiva. No entanto, para que o Sistema de Pagamento por Qualidade cumpra com seu objetivo, é necessário a aceitação e entendimento dos produtores. Além disso, é fundamental que a indústria ofereça a seus produtores, assistência e acompanhamento técnico, garantindo a efetiva melhora na qualidade.

Diante disso, este trabalho teve como objetivo principal, analisar os impactos gerados por meio da implantação de um Sistema de Pagamento por Qualidade do leite em uma Cooperativa da Agricultura Familiar localizada em Cascavel-PR. Que foi alcançado por meio 
de entrevistas com os representantes da Cooperativa e com os produtores que participam do seu quadro social, que denotaram suas opiniões sobre o assunto.

No transcorrer da pesquisa, foi possível compreender a importância do Sistema de Pagamento por Qualidade em ser associado com o trabalho social realizado por uma Cooperativa da Agricultura Familiar, promovendo assistência e auxílio técnico. Essas iniciativas, garantem a evolução dos seus cooperados. Para ambas as partes, o pagamento por qualidade é uma ferramenta motivadora para a melhoria da qualidade, que cumpre com seu objetivo.

O Sistema de Pagamento por Qualidade promoveu impactos positivos, para às duas partes entrevistadas, no aspecto socioeconômico e técnico. O pagamento por qualidade, não só promove a melhora na qualidade do leite, mas também, proporciona incentivos para o crescimento econômico dos cooperados e da Cooperativa. Além, de aproximar a relação entre o cooperado e a Cooperativa, que buscam juntos vencer os desafios do mercado.

No que se refere aos impactos negativos relacionados ao Sistema de Pagamento por Qualidade do leite, não houve nenhuma menção. A única controvérsia registrada, é de um único produtor que não acredita que a Cooperativa realiza o pagamento por qualidade, porque não está registrado em nota. Os outros impactos estão relacionados ao modelo de gestão da Cooperativa.

Como sugestão para futuras pesquisas, sugere-se explanar o posicionamento dos produtores, em relação ao pagamento ser realizado por qualidade e por cota de volume. Apesar de não ser o foco principal da pesquisa, foi muito evidenciado pelos produtores que fazem parte de uma Cooperativa voltada para a agricultura familiar. Alguns defendem que o pagamento por cota de volume promove a desigualdade e que a Cooperativa acaba perdendo seu objetivo, porém a quem diga que o pagamento por cota de volume é necessário para o reconhecimento dos que investe em volume e como ferramenta de fidelização.

\section{REFERÊNCIAS}

ÁLVARES, J. G. Pagamento do leite por sólidos. In: ZOCCAL, R.; CARVALHO, L.A.; MARTINS, P. C. A inserção do Brasil no Mercado internacional de lácteos. Juíz de Fora: Embrapa Gado de leite, 2005, p. 129-140. Disponível em: https://ainfo.cnptia.embrapa.br/digital/bitstream/item/164236/1/Pecuaria-de-leite-noBrasil.pdf Acesso em: 25 set. 2020.

BARDIN, L. Análise de conteúdo. São Paulo: Edições 70, 2011.

BARROS, G. S. C. et al. Sistema agroindustrial do leite no Brasil. Brasilia: EMBRAPA, 2000.

BAUER, M. W.; GASKELL, G. Pesquisa qualitativa com texto, imagem e som: um manual prático. 2.ed. Petrópolis, RJ: Vozes. 2002. Disponível em: https://www.docsity.com/pt/bauer-e-gaskell-2002/4887211/. Acesso em: 25 set. 2020. 
BRASIL. Ministério da Agricultura, Pecuária e Abastecimento. Instrução Normativa $\mathrm{n}^{\mathrm{o}}$ 37, de 18 de abril de 2002. Instituir a Rede Brasileira de Laboratórios de Controle da Qualidade do Leite, com objetivo de realizar análises laboratoriais para fiscalização de amostras de leite cru, recolhidas em propriedades rurais e em estabelecimentos de laticínios. Diário Oficial da União, Brasília (DF), 19 abr. 2002a. Disponível em: https://www.gov.br/agricultura/ptbr/assuntos/insumos-agropecuarios/insumos-agricolas/sementes-e-mudas/legislacao Acesso em: 10 mar. 2018.

BRASIL. Ministério da Agricultura, Pecuária e Abastecimento. Instrução Normativa $\mathrm{n}^{\circ}$ 51, de 18 de setembro de 2002. Dispõe sobre regulamentos técnicos de produção, identidade, qualidade, coleta e transporte de leite. Diário Oficial da União, Brasília (DF), 20 set. 2002b. Disponível em: https:/www.camara.leg.br/proposicoesWeb/prop_mostrarintegra;jsessionid= 9967695C21370A24B30290D131210A6A.node1 codteor $=141673 \&$ filename $=$ LegislacaoCita da+-INC+611/2003 Acesso em: 10 mar. 2018.

BRASIL. Ministério da Agricultura, Pecuária e Abastecimento. Instrução normativa $\mathrm{n}^{\circ}$ 62, de 29 de dezembro de 2011. Diário Oficial da União, 30 dez. 2011. Disponível em:

$<\mathrm{http}$ ://sistemasweb.agricultura.gov.br/sislegis/action/detalhaAto.do?method=consultarLegisl acaoFederal> Acesso em: 10 mar. 2018.

BRASIL. Ministério da Agricultura, Pecuária e Abastecimento. Instrução normativa n. 76, de 26 de novembro de 2018. Diário Oficial da União, 30 nov. 2018a. Disponível em: $<$ http://www.in.gov.br/materia//asset_publisher/Kujrw0TZC2Mb/content/id/52750137/do120 18-11-30-instrucao-normativa-n-76-de-26-de-novembro-de-2018-52749894IN\%2076> Acesso em: 29 ago. 2019.

BRASIL. Ministério da Agricultura, Pecuária e Abastecimento. Instrução normativa n. 77, de 26 de novembro de 2018. Diário Oficial da União, 30 nov. 2018b. Disponível em: $<$ http://www.in.gov.br/materia//asset_publisher/Kujrw0TZC2Mb/content/id/52750141/do121 8-11-30-instrucao-normativa-n-77-de-26-de-novembro-de-2018-52749887> Acesso em: 29 ago. 2019.

BOTARO, B. G.; GAMEIRO, A. H.; SANTOS, M. V. Quality based payment program and milk quality in dairy cooperatives of Southern Brazil: an econometric analysis. Scientia Agricola, v. 70, n. 1, p. 21-26, 2013. DOI: https://doi.org/10.1590/S010390162013000100004

BREITENBACH, R.; PARIZOTTO, J. Quais as potencialidades e entraves para o programa nacional de alimentação escolar em Getúlio Vargas/RS? DRd - Desenvolvimento Regional em debate, v. 10, p. 590-608, 19 jun. 2020. DOI: https://doi.org/10.24302/drd.v10i0.2760

CARBONERA, R. et al. Diversidade de sistemas produtivos e sustentabilidade na agricultura. DRd - Desenvolvimento Regional Em Debate, v. 10, p. 98-118. 2020. DOI: https://doi.org/10.24302/drd.v10i0.2505

CLEMENTE, E. C.; HESPANHOL, A. N. Reestruturação da cadeia produtiva do leite: A especialização do produtor é a solução? São Paulo, Encontro nacional de grupos de pesquisa - ENDRUP, 2008. p. 205-225. Disponível em: http://www.seer.ufu.br/index.php/campoterritorio/article/download/11923/6971/. Acesso em: 24 set. 2020 . 
CONSELEITE PARANÁ. Site da empresa. 2019. Disponível em: https://conseleitepr.com.br/ Acesso em: 18 nov. 2019.

COSTA, B. A. L.; AMORIM JUNIOR, P. C. G.; SILVA, M. G. As Cooperativas de agricultura familiar e o mercado de compras governamentais em Minas Gerais. Revista de Economia e Sociologia Rural, v. 53, n.1, p. 109-125, jan./mar. 2015. DOI: https://doi.org/10.1590/1234-56781806-9479005301006

DÜRR, J. W. Programa nacional de melhoria da qualidade do leite uma oportunidade única. In: CONGRESSO BRASILEIRO DE QUALIDADE DO LEITE; 1. 2004. Passo Fundo. Anais..., Passo Fundo, 2004. Disponível em: https://docplayer.com.br/14571150-Programanacional-de-melhoria-da-qualidade-do-leite-uma-oportunidade-unica.html Acesso em: 24 set. 2020.

EKMAN, J. Payment according to quality, World Health Organization-WHO, 2002. Disponível em: https://www.who.int/whr/2002/en/ Acesso em: 05 abr. 2019.

EMBARÉ. Site da empresa. 2019. Disponível em:

https://www.embare.com.br/boletimdequalidade/\%EF\%BB\%BFnova-tabela-de-bonificacaodo-leite/ Acesso em: 05 abr. 2019.

FAGNANI, R. Vale a pena ler de novo! "Resumão das INs 76 e 77: elas estão chegando! São Paulo: Milkpoint, 2019. Disponível em: https://www.milkpoint.com.br/colunas/rafaelfagnani/resumao-das-ins-76-e-77-elas-estao-chegando-212785/ Acesso: 04 de out. 2019.

FARINÃ, L. O.; BUSARELLO, J. J. Práticas Agropecuárias para Obtenção de Leite. In: PINTO, C. L. O et al. Qualidade Microbiológica do Leite cru. 22. ed. Viçosa: EPAMIG Zona da Mata, 2013. p. 13 - 56.

FONSECA, L. F. L. Pagamento por qualidade: situação atual e perspectivas para o setor lácteo brasileiro. São Paulo: Milkpoint 2001. Disponível em: https://www.milkpoint.com.br/noticias-e-mercado/panorama-mercado/pagamento-por qualidade-situacao-atual-e-perspectivas-para-o-setor-lacteo-brasileiro-8211-parte-01 8089n.aspx Acesso em: 05 abr. 2019.

GIGANTE, M. L. Importância da qualidade do leite no processamento de produtos lácteos. In: DÜRR, J. W. (Org.). O compromisso com a qualidade do leite no Brasil. Passo Fundo, RS: UPF, 2004. p. 76-88. Disponível em: https://repositorio.usp.br/item/001408010 Acesso em 25 set. 2020 .

GIL, A. C. Como elaborar projeto de pesquisa. 5. ed. São Paulo: Atlas, 2010.

LAKATOS, E. M.; MARCONI, M. A. Metodologia científica. 6. ed. São Paulo: Atlas, 2011.

MACHADO, P. F.; PEREIRA, A. R.; SARRIÉS, G. A. Efeitos da contagem de células somáticas na qualidade do leite e a atual situação de rebanhos brasileiros. Revista do Instituto de Laticínios Cândido Tostes, Juiz de Fora, MG, v. 54, n. 309, p. 10-16, 1999. Disponível em: https://www.revistadoilct.com.br/rilct/index Acesso: 30 de abr. 2019. 
MARCHAND, P.; RATINAUD, P. L'analyse de similitude appliqueé aux corpusteels: les primaries solicialistes pour l'election présidentielle française (septembre-octobre, 2011). In: Actes des Ileme Journé es internationalesd' Analyse statistique des DonnéesTextuelles. JADT: Liége, 2012. p. 687-699.

MARTINS, P. C. Qualidade do leite: qual o estímulo? São Paulo: Milkpoint, 2003. Disponível em: https://www.milkpoint.com.br/noticias-e-mercado/panoramamercado/qualidade-do leite-qual-o-estimulo-8132n.aspx Acesso: 30 de abr. 2019.

MORAES, B. M. M.; BENDER FILHO, R. Mercado brasileiro de lácteos: análise do impacto de políticas de estímulo à produção. Revista de Economia e Sociologia Rural, v. 55, n. 4, p. 783-800, out/dez 2017. DOI: https://doi.org/10.1590/1234-56781806-94790550410.

MU, L. Y. et al. Milking the quality test: Improving the milk supply chain under competing collection intermediaries. Management Sci, v. 62, n. 5, p. 1259-1277. 2016. DOI: 10.1287/mnsc.2015.2171.

MU, L.Y.; DAWANDE, M.; MOOKERJEE, V. Shaping the Values of a Milk Cooperative: Theoretical and Practical Considerations. Production and Operations Management, v. 28, n. 9, p. 2259-2278. 2020. DOI: https://doi.org/10.1111/poms. 13049.

OJIAGU, N. C.; UCHENNA, C. O. Effects of membership of cooperative organisations and determinants on farmer-members' income in rural Anambra State, Nigeria. International Journal of Scientific \& Technology Research, v. 4, n. 8, p. 28-35. 2015. DOI: 10.12691/jaaepa-2-1-7.

OLIVEIRA, A. A. Modelo para gerenciamento do pagamento por qualidade na indústria de laticínios. 2012. Dissertação (Programa de Pós-Graduação em Ciência e Tecnologia de Alimentos) - Universidade Federal de Viçosa. 2012. Disponível em:http://www.locus.ufv.br/bitstream/handle/123456789/2923/texto\%20completo.pdf?sequen ce $=1$ Acesso: 30 de abr. 2019.

PARANHOS, L. G. Instrução Normativa 76 e 77: novas normas para cadeia do leite. São Paulo: Milkpoint, 2019. Disponível em: https://www.milkpoint.com.br/canaisempresariais/ourofino/instrucao-normativa-76-e-77-novas-normas-para-cadeia-doleite214676/ Acesso: 04 de out. 2019.

POPESCU, A.; ANGEL, E. Cow raw milk quality and its factors of influence in relationship with milk price. Management, Economic Engineering in Agriculture and rural development, v. 19, n. 1, p. 421-440, 2019. Disponível em: http://managementjournal.usamv.ro/index.php Acesso em 25 set. 2020.

REINERT, M. Alceste, une méthodologie d'analyse des données textuelles et une application: Aurelia de Gerard de Nerval. Bulletin de Methodologie Sociologique, v. 26, p. 24-54, 1990. DOI: http://doi.org/10.1177/075910639002600103

SAMPIERI, R. H.; COLLADO, C. F.; LUCIO, M. P. B. Metodologia de pesquisa. 5. ed. Porto Alegre: Penso, 2013. 
SANTOS, M. V. A melhoria da qualidade do leite e a IN 51. São Paulo: Milkpoint, Abr. 2011a. Disponível em < https://www.milkpoint.com.br/colunas/marco-veiga-dos-santos/amelhoria-da-qualidade-do-leite-e-a-in-51-71764n.aspx?r=1525702324\#> Acesso em: 20 mar. 2019.

SANTOS, M. V. Como o pagamento influencia a qualidade do leite? São Paulo: Milkpoint, 2011b. Disponível em: https://www.milkpoint.com.br/colunas/marco-veiga-dossantos/como-o-pagamento-influencia-a-qualidade-do-leite-73858n.aspx Acesso: 30 de abr. 2019.

SANTOS, M. V.; FONSECA, L. F. L. Importância e efeito de bactérias psicrotróficas sobre a qualidade do leite. Revista Higiene Alimentar, v. 15, n. 82, 2001, p. 13-19. Disponível em: http://higienealimentar.com.br/82-2/ Acesso em: 24 set. 2020.

SILVA, R. O. P.; LISERRE, A. M. Intervenção do Estado nos Preços do Leite e suas Consequências na Produção Análises e Indicadores do Agronegócio. Secretaria de Agricultura e Abastecimento Instituto de Economia Agrícola: São Paulo, ago. 2009. Disponível em: $<$ http://www.iea.sp.gov.br/out/TerTexto.php?codTexto $=11726 \geq$ Acesso em: 05 mai. 2018.

SLACK, N.; CHAMBERS, S.; JOHNSON, R. Administração da Produção. 1. ed. São Paulo: Atlas, 1997.

SAUSEN, J. F. C. L. et al. Gestão humanizada aplicada aos princípios e práticas cooperativistas: estudo de caso em uma agência SICREDI. DRd - Desenvolvimento Regional em debate, v. 9, p. 563-582, 19 set. 2019. DOI: https://doi.org/10.24302/drd.v9i0.2242.

TRABAQUINI, K. et al. O campo nativo e sua relação com a produção do queijo artesanal serrano em Santa Catarina. DRd - Desenvolvimento Regional em debate, v. 9, n. Ed. esp. 2, p. 4-23, 20 dez. 2019. DOI: https://doi.org/10.24302/drd.v9iEd.\%20esp.\%202.2512.

VIEIRA, E. L.; BASSO, D.; KRÜGER, N. R. Aquisições da agricultura familiar e qualidade dos alimentos fornecidos na rede escolar municipal de Catuípe/RS. DRd - Desenvolvimento Regional em debate, v. 10, p. 461-489, 22 maio 2020. DOI: 10.24302/drd.v10i0.2833.

WINCK, C. A. Impactos do pagamento pela qualidade na cadeia produtiva do leite na região oeste de Santa Catarina. 2012. Tese de doutorado (Programa de Pós-Graduação em Agronegócios do Centro de Estudos e Pesquisas em Agronegócio) - Universidade Federal do Rio Grande do Sul, Porto Alegre, 2012. Disponível em: https://lume.ufrgs.br/handle/10183/60510 Acesso em 25 set. 2020.

ZÜGE, R. As novas legislações para produção de leite: estamos prontos? São Paulo: Milkpoint, 2019. Disponível em: https://www.milkpoint.com.br/colunas/na-mira/as-novaslegislacoes-para-producao-de-leite-estamos-prontos-212930/ Acesso: 04 de out. 2019. 